\title{
LO SPAZIO SACRO NEGLI EDIFICI CULTUALI PALEOCRISTIANI DELL'ALTO ADRIATICO
}

\section{GIUSEPPE CUSCITO}

UDC 726.54.033(497.5)

247.2

Original scientific paper

Manuscript received: 01. 12. 1994.

Revised manuscript accepted: 01. 04. 1995.

G. Cuscito

Università di Trieste

Italia

Il problema dell'arredo liturgico nella basilica cristiana é correlato a quello dello spazio liturgico nonché dello svolgimento del rito. Per analisi del problema sarà necessario seguire un ordinato procedimento: - dei più importanti elementi che costituiscono lárredo liturgico e alla loro collocazione all'interno del luogo sacro; - delle testimonianze dell fonti; - della distribuzione cronologica e ambientale dei monumenti considerati.

\section{Premessa}

Come si sa, tra gli elementi che costituiscono l'arredo liturgico, maggior importanza spetta all'altare e alla cattedra, i due poli attorno a cui ruota lo svolgimento del rito: Cristo misticamente presente sull'altare e il vescovo, continuatore dell'opera apostolica. Perciò, in funzione del tema proposto, è degna di studio la collocazione riservata soprattutto a questi due elementi, anche se non vanno trascurati apprestamenti di minore rilievo, come l'ambone o la mensa per le offerte che, in molte basiliche orientali (ShaveiZion, Kaoussie, Bethlehem, Kurnub, Evron, ecc.), occupavano un posto fuori dal presbiterio, distinto sul pavimento musivo dai soliti signa Christi. ${ }^{1}$

Occorre dire anche che il complesso eretto dal vescovo Teodoro ad Aquileia è unico sulla costa adriatica per antichità e per alcune soluzioni ancora provvisorie: perciò è proprio di questa antichità ed unicità che bisogna tenere conto nel considerare la sistemazione presbiteriale delle aule primitive, come rilevava il Tavano. ${ }^{2}$ Egli era infatti convinto di trovarsi di fronte a una fase "sperimentale" delle costruzioni cristiane aquileiesi, alla quale appartennebbero anche le primitive aule di Parentium, che però non sembrano presentare tracce di recinzione fissa.

Prima di avviare una qualsiasi indagine sull'arredo liturgico e sulle sue modificazioni fra Tarda Antichità e Alto Medioevo, occorre precisare che qui intendiamo riferirci, più che alla suppellettile liturgica generalmente associata alle cosiddette arti minori, a tutta quella serie di apprestamenti mobili o fissi adottati dalla comunità cristiana nei propri edifici di culto per consentire un adeguato svolgimento del rito. Da ciò emerge la connessione dell'arredo con lo spazio più propriamente liturgico dell'edificio cultuale - anche se ogni fedele, pur al di fuori di certi spazi riservati al clero, più che assistere, partecipa alla funzione liturgica del celebrante - e con 'organizzazione del rito, che, al di là delle poche costanti, presenta una ricca serie di caratteristiche variabili a seconda dei condizionamenti storici e culturali. Non meraviglia dunque che i mutamenti del rito provochino variazioni nell'organizzazione dello spazio sacro e conseguentemente nell'adozione dell'arredo liturgico.
Ne è testimone in modo particolare Aquileia e Parentium, dove peraltro le varianti risultano più significative fra i secoli IV e VI all'interno della Tarda Antichità che non fra Tarda Antichità e Alto Medioevo, se prescindiamo dai caratteri della scultura decoartiva dipendenti dal gusto e dalle scelte estetiche. Dopo una sistemazione del rito nel corso del sec. IV - il secolo d'oro della patristica - con una netta distinzione tra clero e popolo e con un'enfatizzazione del posto del clero che postula uno spazio adeguato, sembrano prevalere i caratteri di continuità fino all'Alto Medioevo quando semmai si accentua anche da noi, per influenza dell'Oriente, la disciplina dell'arcano e l'iconostasi - nata dalla pergula paleocristiana - accentua la distinzione e si pone tra clero e popolo come un diaframma venuto meno solo di recente in relazione al movimento liturgico postconciliare.

Per avviare una rinnovata analisi del problema, già sollevato con diverse conclusioni dal Mirabella Roberti, dal Brusin, dal Tavano e da chi scrive relativamente alla posizione dell'altare nelle basiliche altoadriatiche, è necessario seguire, a mio parere, un ordinato procedimento che tenga conto:

- dei più importanti elementi che ovunque nel mondo cristiano antico e tuttora costituiscono l'arredo liturgico (altare, cattedra, banco presbiteriale, ambone) e della loro ubicazione all'interno del luogo sacro;

- delle testimonianze delle fonti;

- della distribuzione cronologica e ambientale dei monumenti considerati.

\section{LA TESTIMONIANZA DELLE FONTI}

Passo ora alla trattazione dei singoli punti, nella speranza di poter formulare delle ipotesi di lavoro senza pretendere di giungere a soluzioni definitive, assai infrequenti per indagini di questo tipo.

Analizziamo ora attentamente le testimonianze letterarie, quali ci vengono offerte dalle opere dei più antichi scrittori ecclesiastici. 
Eusebio di Cesarea celebra la sapiente e mirabile costruzione della basilica di Tiro, dove aveva pronunciato un elegante discorso inaugurale su invito del vescovo Paolino.

"Terminata così la costruzione del tempio, (Paolino) ha provvisto questo di sedili molto elevati per onorare quelli che vi presiedono e inoltre di banchi disposti ordinatamente per tutto il tempio con convenienza. Soprattutto ha eretto al centro il Santo dei Santi cioè l'altare e, perchè ad esso non accedesse la moltitudine, lo ha chiuso con transenne lignee, nella parte superiore lavorate con straordinaria finezza artistica, per modo che offrisse agli spettatori una visione stupenda". ${ }^{3}$ Da questo testo, declamato subito dopo il 313 e utilizzato nella Storia ecclesiastica dopo la vittoria di Costantino su Licinio (323), veniamo a sapere che l'altare della basilica di Tiro fu eretto al

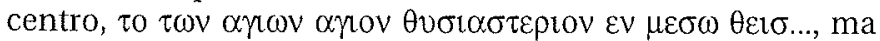
privi di riscontri archeologici, ignoriamo se l'autore abbia voluto riferirsi al centro del presbiterio o della navata; ad ogni modo è interessante rilevare la notizia di una recinzione con transenne lignee finemente intagliate per proteggere l'altare dalla moltitudine che non vi doveva accedere. ${ }^{4}$

Di qualche decennio più tardi - se, come pare ormai assodato, va riferita a Niceta vescovo di Remesiana (città della Dacia Mediterranea soggetta alla provincia della Mesia e situata sulla strada principale che metteva in comunicazione l'Europa occidentale con Costantinopoli) piuttosto che a Niceta di Aquileia ${ }^{5}$ è un'altra testimonianza che non riguarda propriamente l'altare ma l'uso di transenne lignee per separare nella basilica zone riservate a ordini particolari di fedeli; Niceta, nel suo Libelus ad virginem lapsam, si rivolge a una vergine velata che, dopo aver consacrato a Dio la sua vita, era scivolata nella colpa e, ricordandole gli onori che le erano dovuti in forza della sua singolare condizione, tenta di suscitare in lei la vergogna e il pentimento con queste parole: Nonne vel illum locum tabulis separatum, in quo in ecclesia stabas recordari debuisti, ad quem religiosae matronae et nobiles certatim currebant, tua oscula petentes quae sanctiores et digniores te erant? Nonne vel praecepeta quae oculis tuis ipse scriptus paries ingerebat, recordari de buisti? ${ }^{6}$ Anche qui dunque per separare dal resto un posto destinato a particolari ordini di fedeli, troviamo menzionato l'uso di recinzioni lignee che portavano scritti, forse intagliati, versetti biblici allusivi alla condizione della verginità.

Per la seconda metà del secolo IV possediamo al riguardo una preziosa testimonianza di Sozomeno, note autore di una Storia ecclesiastica fra il 439 e il 450 , secondo cui risulta che Ambrogio di Milano fissò la sede dell'imperatore nella cattedrale $\pi \rho \circ \tau \omega \vee \delta \rho \circ \varphi \alpha \kappa \tau \omega \vee ~ \tau o v ~ t \varepsilon \rho \alpha \tau c t o v$ (ante cancellos altaris), contrariamente a un costume invalso ex assentatione vel ex disciplinae corruptione che lo peneva $\varepsilon v \tau \omega$ เ $\varepsilon \rho \alpha \tau \varepsilon i \omega$ (intra consepta altaris). ${ }^{7}$ Anche da qui dunque risulta che la sede dell'altare era recinta da transenne.

Analoghe testimonianze possiamo derivare dal tractatus $X X X$ rivolto da Zenone di Verona, sul finire del secolo IV, ai competentes della sua comunità: egli li invita al fonte battesimale, dove la chiesa è pronta a generarli non foetidis cunis sed suave redolentibus sacri altaris feliciter enutritura cancellis; lo stesso commentatore del testo pubblicato dal Migne ${ }^{8}$ fa rilevare come allora nelle chiese di Verona l'altare fosse recinto da cancelli affinchè la moltitudine dei fedeli accostandosi tumultuosamente all'altare, non turbasse il sacerdote. E se la seconda basilica della capitolare con la lunga solea, di cui diremo, dovesse essere riferita a Zenone, come riteneva lo Zovatto secondo un'ipotesi ormai superata, potremo farci un'idea concreta di quei cancelli e del loro sviluppo, che il De Angelis d'Ossat aveva ritenuto di poter collegare proprio con la distri- buzione eucaristica al popolo. ${ }^{9} \mathrm{Ma}$ una rilettura dei dati monumentali sembra ritardare di circa mezzo secolo questo impianto basilicale.

Fra queste ed altre testimonianze letterarie che considerano l'altare al centro dal santuario, distinto dalla moltitudine dei fedeli, l'unica voce fin qui utilizzata in favore della tesi che pone l'altare quasi al centro dell'aula è un passo di Agostino meritevole di attenzione.

Che in molte basiliche africane l'altare si trovi molto avanzato nella navata è un fatto incontestabile, ${ }^{10}$ ma che il dato materiale trovi sicura conferma nella testimonianza di Agostino mi sembra almeno discutibile, tanto più che la stessa cattedrale di Ippona, la basilica maior accoglie l'altare nello spazio della navata immediatamente affacciato all'abside sopraelevata, isolato dal quadratum populi per mezzo di cacelli, come sembrano appunto attestare i dati di scavo e confermare le testimonianze letterarie. ${ }^{11} \mathrm{Nel}$ sermo 132, Agostino esorta i catecumeni alla grazia della rigenerazione e, commentando Giovanni, VI, 56-57 (Caro mea vere esca est... Quimanducat meam camem...), fa delle considerazioni per i fideles e per gli audientes: i primi qui iam manducant carnem Domini...cogitent quid manducent...; i secondi, qui autem nondum manducant et nondum bibunt, ad tales epulas invitati festinent. Per istos dies (le festività pasquali) magistri pascunt Christus quotidie pascit, mensa ipsius est illa in medio constituta. ${ }^{12}$ Quest'ultima espressione, mensai ipsus est illa in medio constituta, cavallo di battaglia per quanti vogliono sostenere la collocazione dell'altare al centro dell'aula nelle più antiche basiliche dell'Africa settentrionale e della regione altoadriatica, mi sembra che, nel contesto e alla luce delle risultanze archeologiche, sia passibile di una interpretazione piuttosto metaforica che letterale, quasi a dire che la mensa di Cristo è accessibile a tutti e che tutti vi si devono accostare, anche se poi per opportunità liturgica essa si colloca entro una zona riservata. Ma qualora il passo di Agostino intendesse alludere alla materiale presenza dell'altare sul centro dell'asse longitudinale della chiesa, per le testimonianze letterarie più su addotte, non siamo autorizzati a ritenerlo privo di una recinzione di transenne: nel secolo IV la celebrazione eucaristica non doveva essere più semplicemente un pasto in comune, ma doveva essere già un rito in cui vescovo e clero svolgevano un ruolo importante tra la moltitudine dei fedeli, che non doveva accalcarsi attorno al Sancta Sanctorum, ove si compivano i sacri misteri. Del resto lo stesso Agostino raccomandava ai peccatori di non accostarsi alla comunione ne proiciantur de cancellis. ${ }^{13}$

\section{TESTIMONIANZE MONUMENTALI}

Ma è ora di passare all'analisi dei monumenti superstiti, dove l'esistenza di significative partizioni del musaico e tracce di imposte per originarie recinzioni pongono pressanti domande. Poiché è assolutamente necessario procedere secondo un rigoroso criterio cronologico, inziamo l'indagine dalle aule teodoriane di Aquileia.

In tutte e tre le aule teodoriane possiamo constatare le tracce di una sicura cancellata che distingueva il presbiterio non accessibile ai laici dal quadratum populi. ${ }^{\text {i4 }} \mathrm{Ma}$, per limitarci alle due aule parallele possiamo facilmente notare sia nella Teodoriana settentrionale (fig. 1) che quella meridionale (fig. 2) un elemento divisorio fra la terza e la quarta campata, previsto dalle cornici del piano musivo e perciò pensato sin dall'inizio: vi si riconosce concordemente l'incassatura per una cancellata delimitante l'area riservata al clero. Le rovine del 

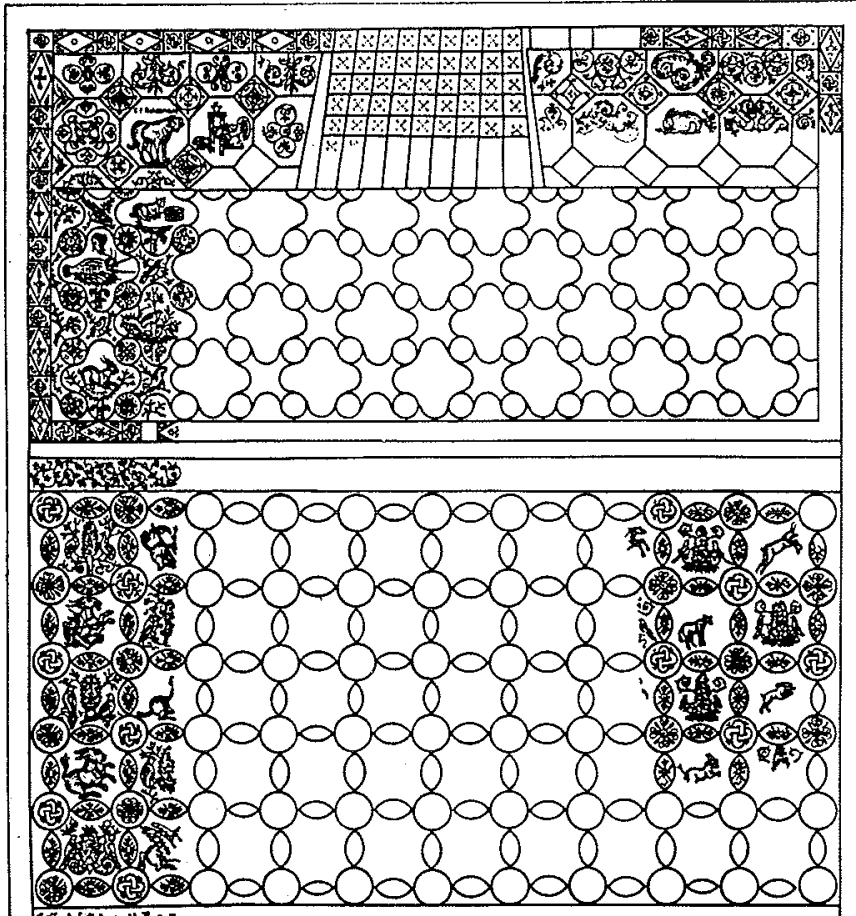

Fens
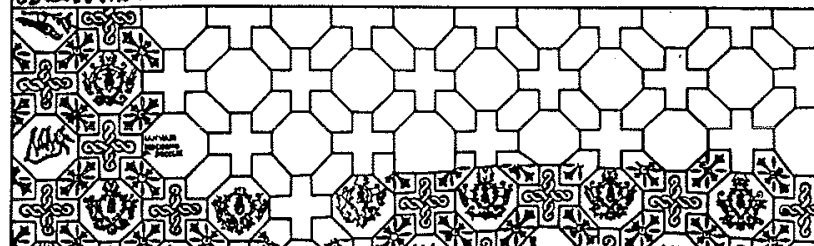
(1)

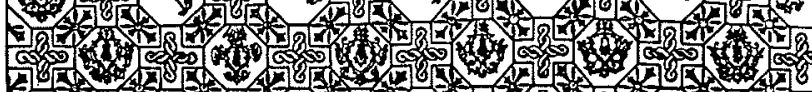
(2) 2 20

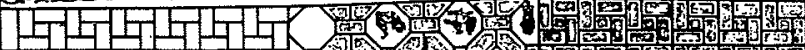

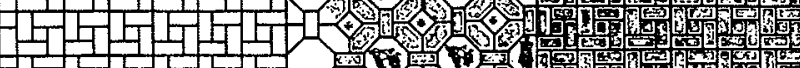
- $-\mathrm{H}-\mathrm{H}-\mathrm{H}$.

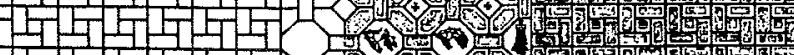

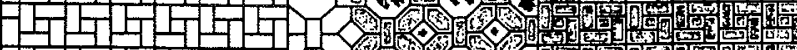

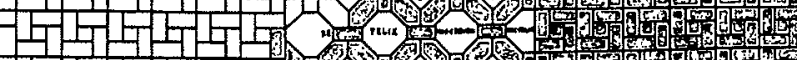
H $\mathrm{H} H \mathrm{H}$.

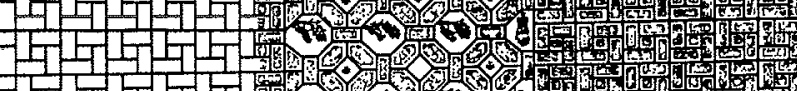

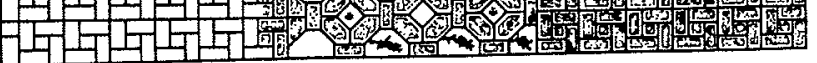

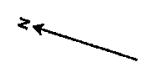

Fig. 1. Aquileta disegno del mosaico dell'aula teodoriana nord.

campanile nell' aula Nord non permettono di individuarne l'ingresso ma il solco scoperto nell'aula Sud indica la presenza di una cancellata fissa (probabilmente lignea) con due stretti ingressi ai lati, come nell' aula intermedia. Recinti presbiteriali con due passaggi ai lati anziché al centro ci sono documentati, per un periodo sucecessivo, in basiliche del Norico, come nella cappella laterale destra della basilica paleocristiana di Tiburnia ${ }^{15}$ (fig. 3). Ora questi sono elementi sufficienti per riconoscere con assoluta certezza la campata orientale delle due aule teodoriane di Aquileia come un riquadro musivo a destinazione liturgica e più precisamente come sede del presbiterio; del resto la scena stessa del mare pescoso con le Storie di Giona, che si estende a tutta la campata orientale

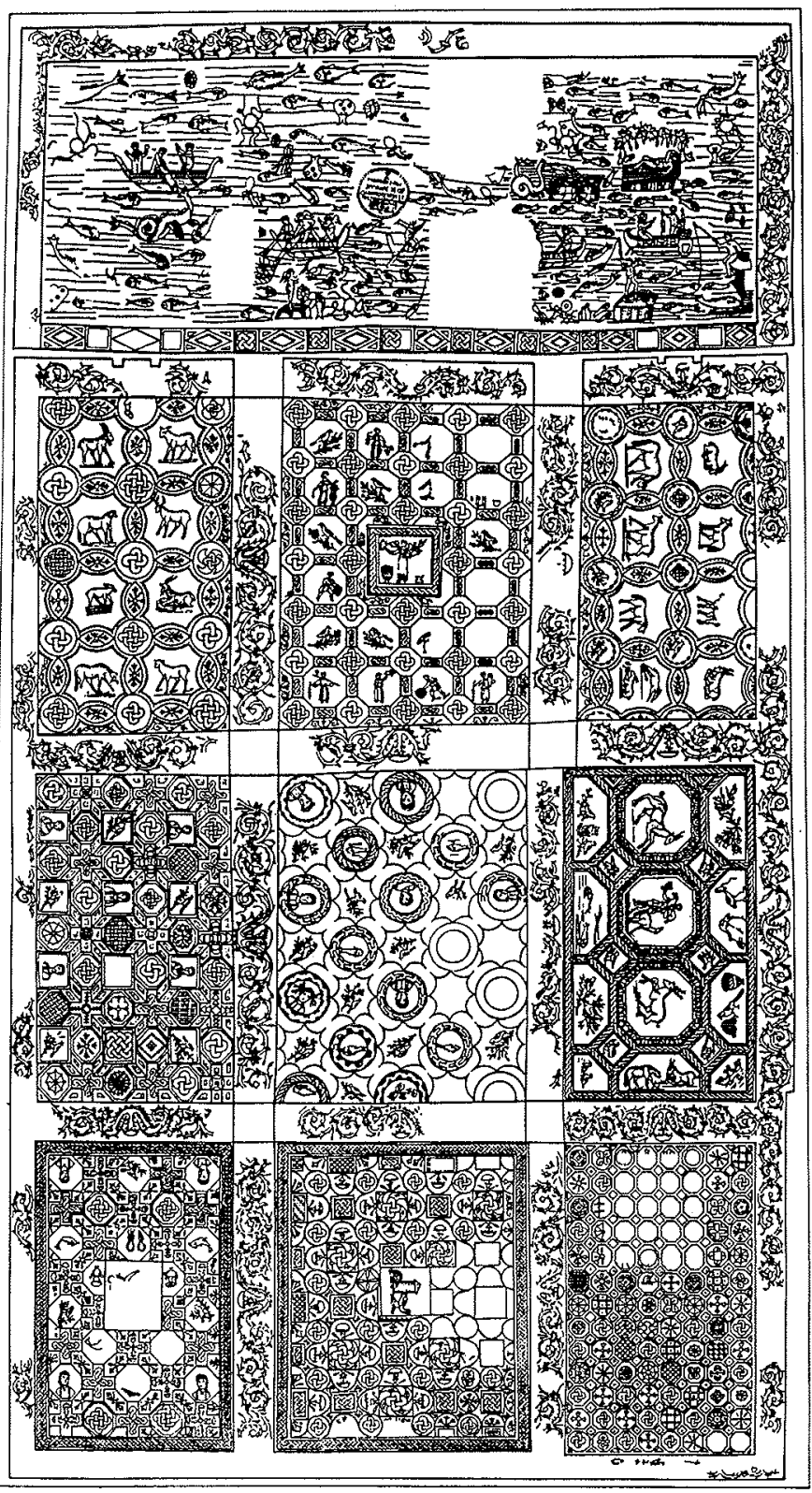

Fig. 2. Aquileia, disegno del mosaico dell'anla teodoriana sud.

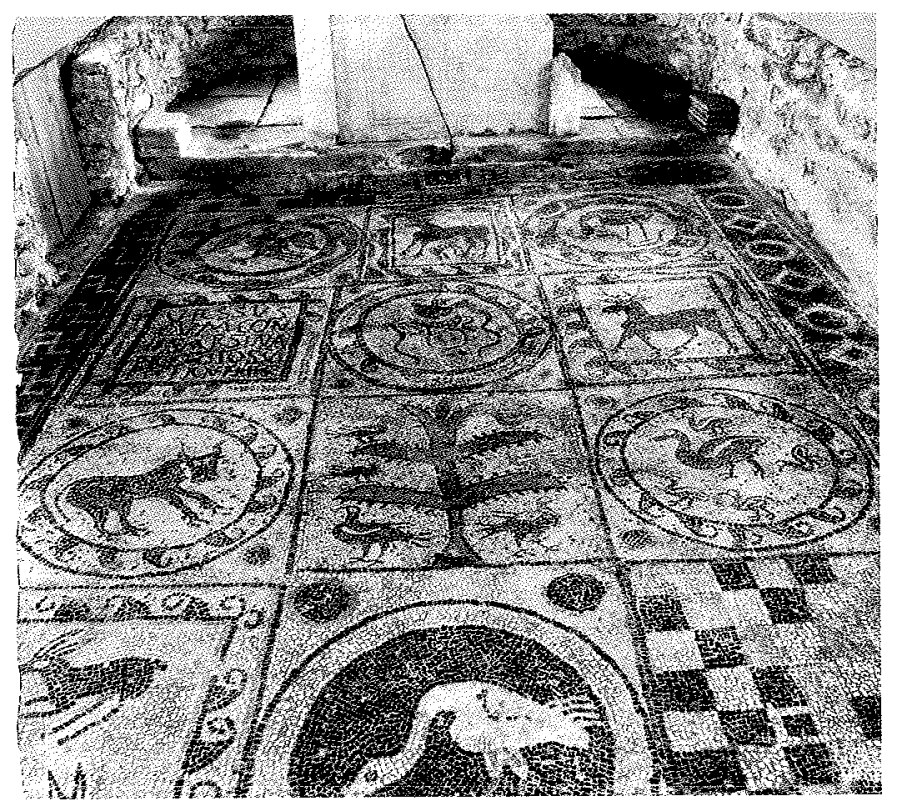

Fig. 3. Tiburnia, capella laterale destra. 
dell'aula Sud è un elemento compositivo particolarmente indiziato a questo riguardo. Al centro della campata orientale dell'aula Nord si ritrova un pannello trapezoidale a quadri e crocette (m 4,70 - 3,85 $\times 2,80$ nella parte superstite), atto a contenere i seggi dei presbiteri e primo indizio di quel banco presbiteriale fisso che nel secolo successivo sarà ricorrente nelle basiliche della metropoli aquileiese. ${ }^{16}$

Fin qui tutti d'accordo in quanto sono i dati archeologici a parlare più che gli archeologi.

I problemi si agitano quando cominciamo a chiederci che cosa fosse accolto nel presbiterio, oltre ai seggi dei presbiteri, e quale delle due aule parallele fosse adibita a catecumeneo, $\mathrm{e}$, in quanto tale, non fornita di altare del sacrificio.

Fu il Mirabella Roberti a sollevare il problema dopo le felici scoperte di Orsera, ${ }^{17}$ partendo dal presupposto di dover riconoscere con ogni probabilità l'aula meridionale come quella della sinassi. Ma, pur ammettendo che per ragioni costruttive e pratiche anche l'aula Nord possa essere stata adibita ad usi cultuali o che la sinassi abbia potuto aver svolgimento completo nelle due aule, il Mirabella Roberti anche ultimamente riteneva opportuno prendere le mosse dall'analisi dell'aula meridionale che, per essere assai più conservata nella sua integrità musiva, può fornirci orientamenti più sicuri. ${ }^{18}$ Qui infatti l'area lungo l'asse longitudinale è conservata interamente e presenta degli emblemata che interrompono il disegno dei tappeti, determinando delle zone di rilievo: il clipeo con l'iscrizione di Teodoro nella IV campata, dove si stende il musaico col mare pescoso e con le Storia di Giona (fig. 4); il riquardo con la Vittoria cristiana (fig. 5), immesso in un tessuto di ottagoni con figure di offerenti, al centro della terza campata, e il riquadro con la Lotta fra il gallo e la tartaruga, al centro della prima campata. Fuori dall'asse longitudinale, il tappeto settentrionale di questa prima campata accoglie al centro un riquadro lacunoso con scena di pesca.

Quello della Vittoria risulta l'emblema di maggior rilievo fra tutti i simboli e le immagini umane: per il Mirabella Roberti deve certo trattarsi del riquadro che, all'inizio, accoglieva l'altare mobile, lo confermerebbero le immagini degli offerenti che circondano il pannello, mentre i rami fioriti con gli uccelli farebbero pensare al versetto del salmo 127: "I tuoi figli siano come virgulti di olivo attorno alla tua mensa". Una prova ulteriore sarebbe fornita dai quattro tasselli inclusi più tardi nel musaico con imposte di un altare a cassa, formato da quattro lastre marmoree con piccole lesene d'angolo per una sistemazione di reliquie sulla fine del secolo IV. Viceversa i quattro rappezzi sull'epigrafe di Teodoro sarebbero stati prodotti dal

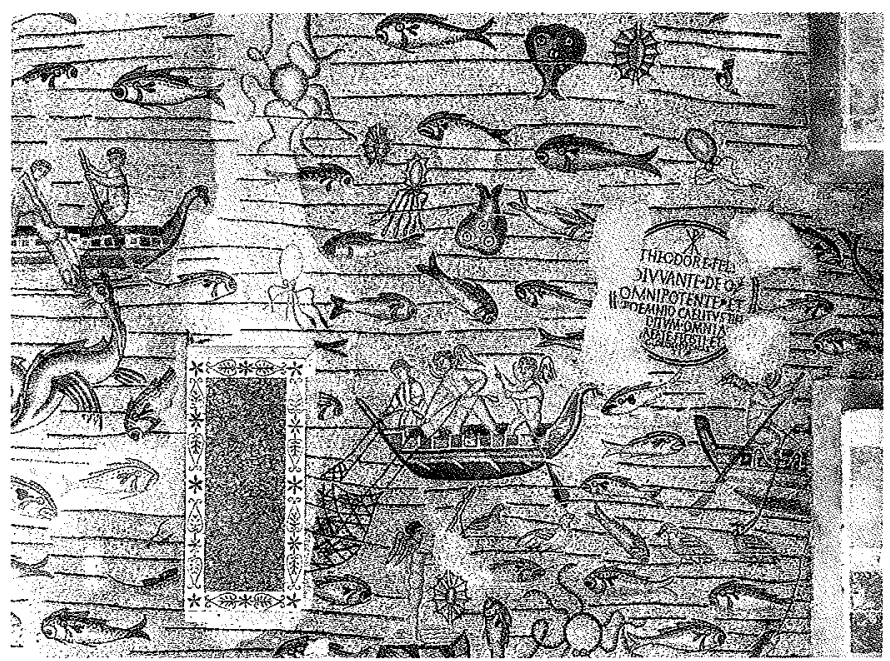

Fig. 4. Aquileia, anla teodoriana sud, Storia di Giona (foto: Ciol).

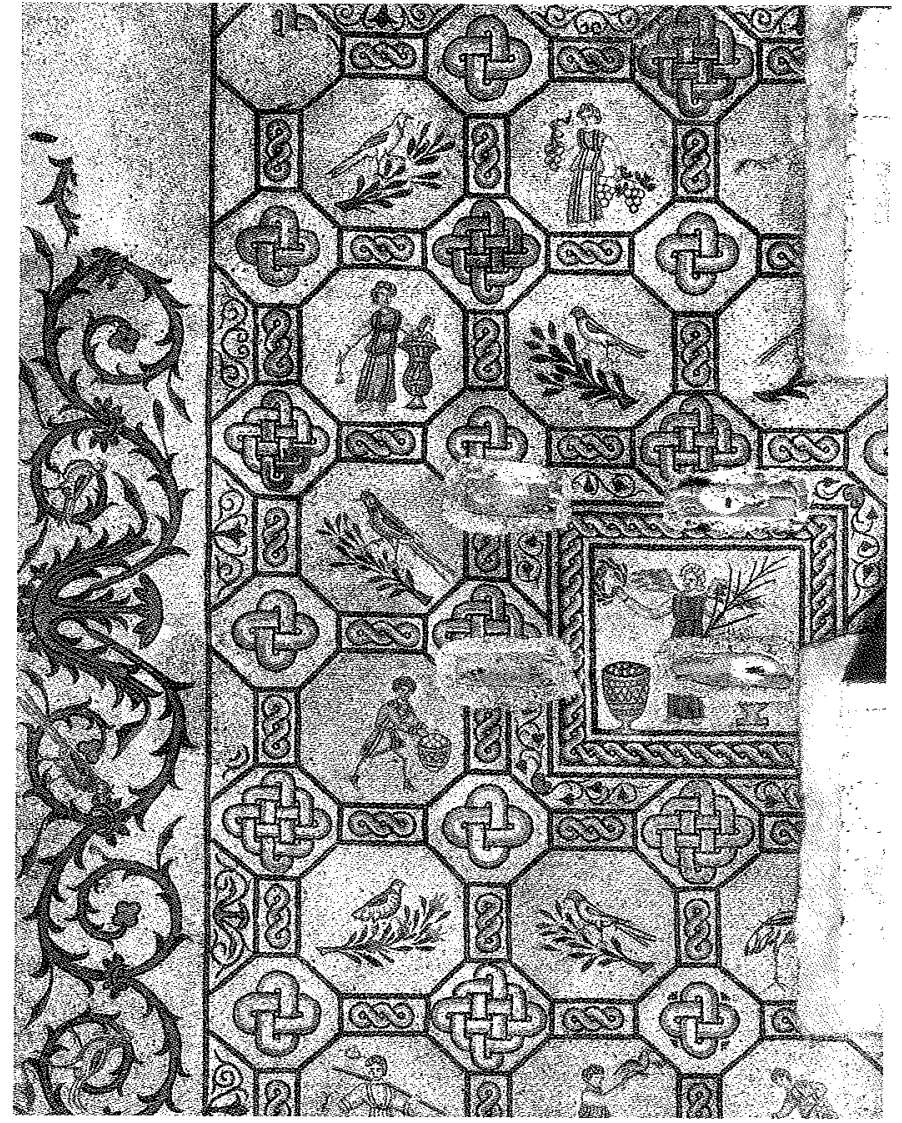

Fig. 5. Aquileia, aula teodoriana sud, Vittoria cristiana (foto: Ciol).

logorio della cattedra episcopale, non dalla impostazione di colonnine per reggere una mensa d'altare, in quanto non sono stati trovati gli zoccoli su cui saldarle secondo una necessità pratica e la prassi costruttiva tradizionale, come si può invece constatare sulla Vittoria e nell'aula intermedia. ${ }^{19}$

Sel'ipotesi del Mirabella Roberti dovesse venir confermata, ci troveremmo di fronte a un riquadro musivo destinato ad accogliere l'altare fuori dal recinto presbeteriale che separava la III dalla IV campata. Inoltre la continuità dei cancella con due sole strette aperture ai lati rilevate anche dal Tavano ${ }^{20}$ avrebbe interrotto quella ideale "via sacra" che collegava l'altare alla cattedra, senza contare che il passaggio del presbiterio all'altare non sarebbe stato agevole tra la moltitudine dei fedeli che potevano affollare l'aula. D'altra parte la presenza di una chiusura trasversale fissa fra la terza e la quarta campata, contemporanea alla stesura del musaico, non può essere revocata in dubbio.

Invece, quando Teodoro costruì l'impianto cultuale, l'asse della IV campata col mare pescoso era lasciato pressoché libero da simboli e da ornamenti particolari (come nell'aula Nord), tanto da dividere asimmetricamente le tre Storie di Giona, che invece avrebbero potuto essere distribuite altrimenti ed esteticamente in modo migliore (una al centro e due ai lati): qui a nostro giudizio - c'era lo spazio necessario per l'altare e per la cattedra; infatti dal centro con l'epigrafe acclamatoria di Teodoro, inserita forse più tardi, al limite orientale della campata, ci sono ancora circa $m 4$ (lo stesso spazio che intercorre ad esempio tra l'altare e la cattedra medievale). D'altra parte inserire nel musiaco un emblema particolarmente prezioso e ricco di significati spirituali come la Vittoria per poi ricoprirlo con un altare sia pur mobile, mi pare contraddittorio, dal momento che le figurazioni principali dovevano assolvere a 
una funzione non solo esornativa ma anche didattico-allegorica. Se poi l'aula fosse sorta come consignatorium e catechumeneum, secondo l'ipotesi dello Gnirs, dell'Egger, e del Bru$\sin ^{21}$ ultimamente ripresa del Menis, ${ }^{22}$ non ci sarebbe la necessità di riconoscervi una sede per l'altare e tanto meno si sentirebbe la mancanza di un passaggio centrale nella cancellata. ${ }^{23}$

Di una cosa possiamo essere certi per ragioni strutturali e compositive: che la campata orientale, occupata interamente da scene di pesca e dalle Storie di Giona e separata dal resto dell'aula per mezzo di una recinzione, costituisce un unico tappeto musivo di grande rilievo riservato al clero: da esso trarrà forse ispirazione, sul finire del secolo, il tessellato del catacumeneo di Orsera. Che in un secondo momento, probabilmente durante la costruzione della grande Postteodoriana Nord e della basilica della Beligna, l'emblema con la Vittoria abbia dovuto sopportare un altare a cassa, forse per la reposizione di venerate reliquie apostoliche in attesa di una basilica martiriale non ancora ultimata, dipende da una necessità sopravvenuta più tardi che non serve a spiegare l'origine del riquadro. ${ }^{24}$

Se altare ci fu nella Teodoriana settentrionale, in quanto possibile aula della sinassi, non c'e ragione di credere che sia stato sistemato fuori dai cancelli (fig. 6): la quarta campata infatti è divisa in due zone per mezzo di una fascetta di tessellato nero tra la sede dei presbiteri col pannello trapezoidale e quella di un possibile altare. ${ }^{25}$ Inoltre la disposizione delle figure di animali campiti nelle geometrie non sembra in relazione con un centro ideale dell'aula ma piuttosto con l'entrata che si apriva sul muro meridionale della stessa; del resto anche nella Teodoriana Sud vedrei la medesima tendenza anziché una relazione delle figure con la Vittoria, come pensa il Mirabella Roberti.

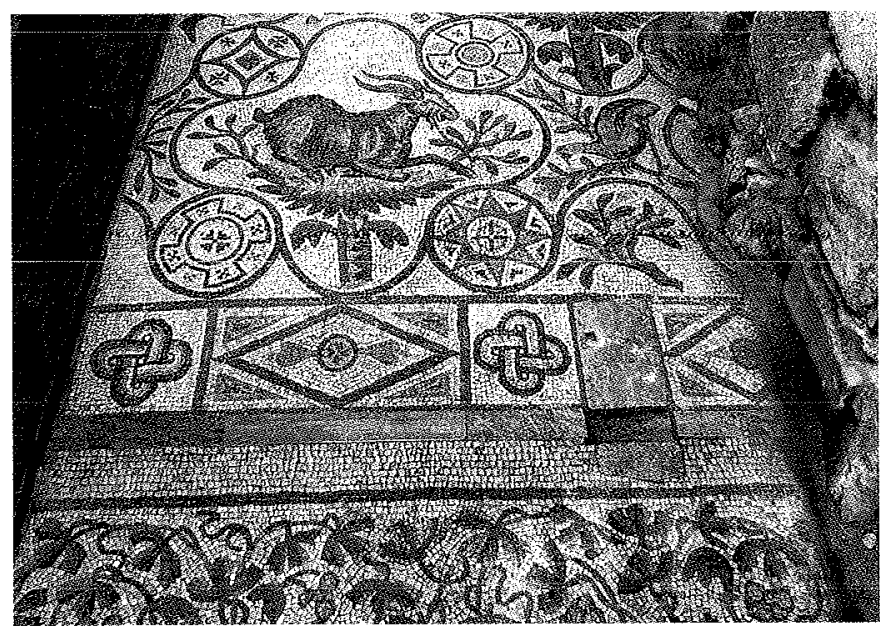

Fig. 6. Aquileia, anla teodoriana nord, mosaico.

Anche il Tavano, che pure aveva rilevato la mancanza di un passaggio al centro della cancellata nella Teodoriana meridionale e quindi la mancanza di una comunicazione diretta tra il riquadro della Vittoria e il presbiterio, parte dal presupposto che quella figurazione tanto importante fosse destinata ad accogliere l'altare e non esclude che la celebrazione del rito sacro avanzasse tra la folla, a meno che l'aula non fosse sorta con funzione di catecumeneo: ci troveremmo così di fronte ad uno sperimentale sviluppo della'area sacra in lunghezza sull'asse longitudinale della chiesa, conforme all'immagine che ci offre la capsella eburnea di Pola (figg. 7-7a) e a quelle soluzioni più "razionali" documentate nelle più tarde basiliche dell'area aquileiese con l'adozione della solea ${ }^{26} \mathrm{Ma}$, se questa ipotesi può essere timidamente avanzata per la Teodoriana

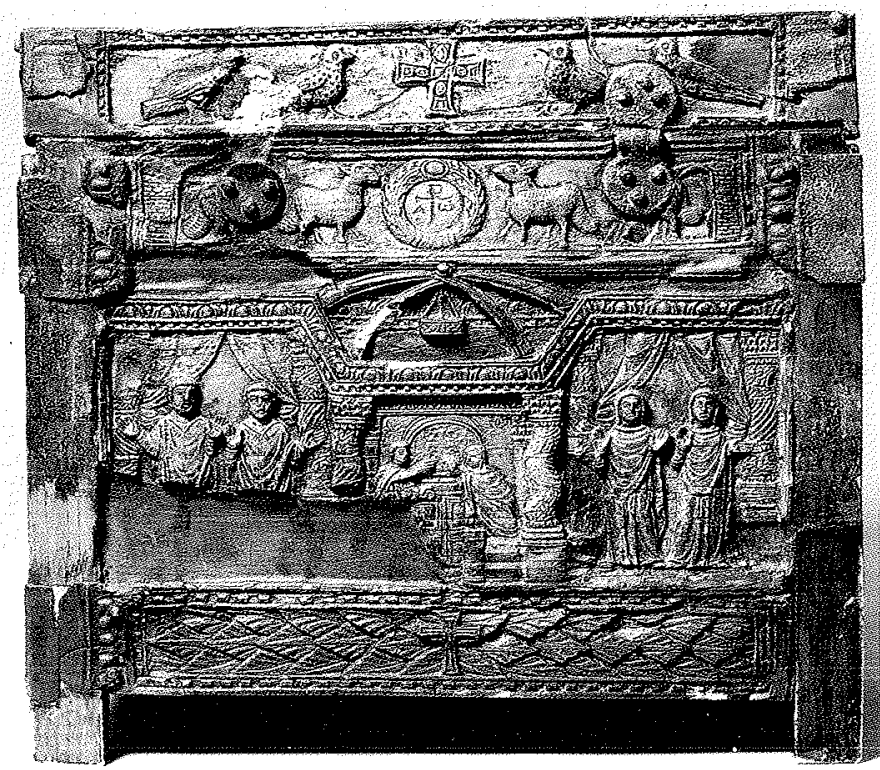

Fig. 7. Pula, capsella eburnea, parte retrostante (Museo archeologico, Venezia).
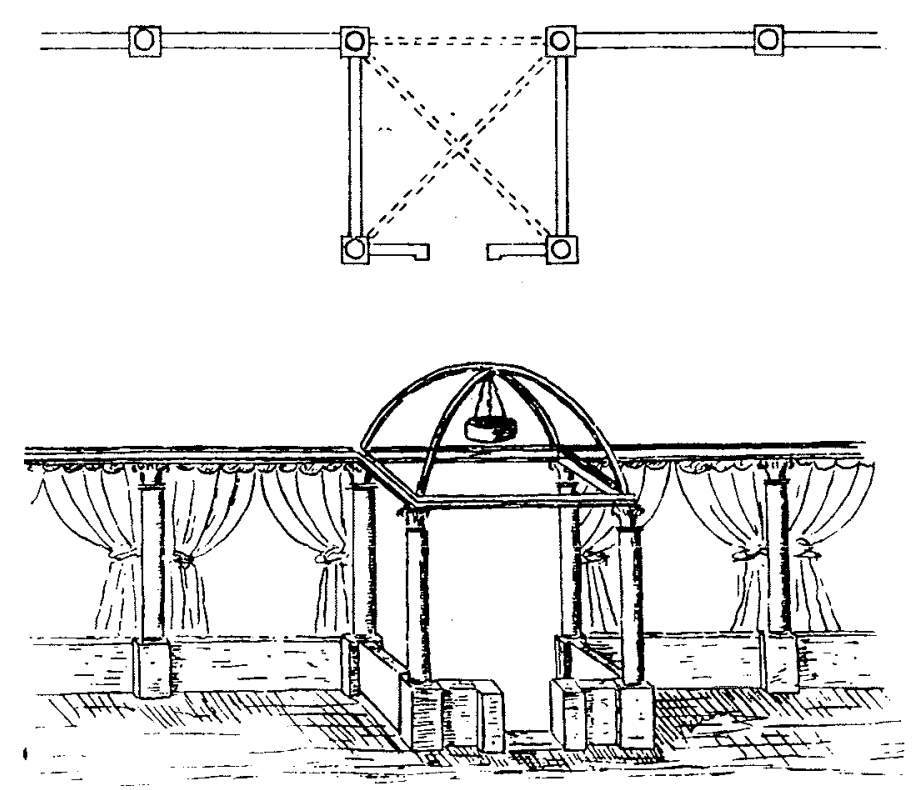

Fig. 7a. Cancelli di presbiterio: tentativi di vicostruzione dello Gnirs sulla base del pannello dello scrigno di Pula.

Nord, dove la rovina del campanile popponiano ha tolto ogni possibile evidenza, resta sempre il fatto che nella Teodoriana Sud questa embrionale digitazione dell'area sacra sarebbe impedita dalla cancellata.

Per la seconda metà del secolo IV, la solea della Postteodoriana settentrionale (fig. 8) documenta - come si vedra - il fenomeno di un allungamento del bema nella navata, ma essa non ha certo la funzione di proiettare in avanti la sede dell'altare - qui già abbastanza avanzato nel quadratum populi forse per l'enorme sviluppo longitudinale dell'edificio - come in talune chiese africane. Viceversa anche in questa basilica, dove lo stile del musaico pavimentale trova il più immediato parallelo con quello dell' aula meridionale di Parenzo ${ }^{27}$ si nota la stretta relazione esistente tra il presbiterio e l'altare entro 


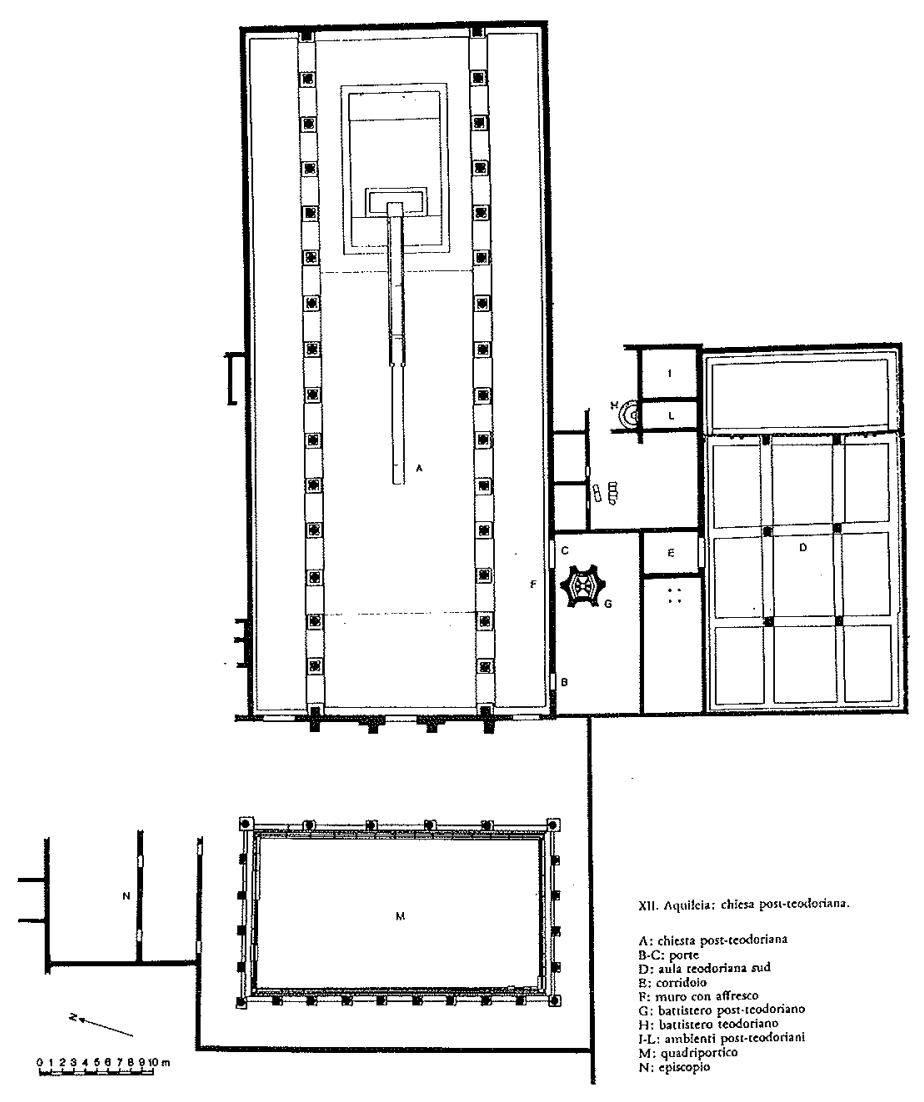

Fig. 8. Aquileia, chiesa post teodoriana (da Bertacchi).

un'unica zona di rilievo. E'questa una grande area di $\mathrm{m}$ $8,92 \times 15,85$, delimitata nel musaico da una cornice a girali, che cinge tre tappeti musivi: quello più orientale era certamente destinato alla cattedra e agli assistenti; in quello centrale a meandri è campita un'altra inquadratura di $\mathrm{m} 5,72 \times 3$, già riconosciuta dal Cecchelli, dal Brusin e dal Mirabella Roberti come sede dell'altare ligneo a ben 17 metri dalla parete orientale; ${ }^{28}$ il riquadro occidentale poteva essere riservato ai lettori e al diacono che guidava la messa corale e dava l'intonazione, secondo una più tarda notizia di Niceta di Remesiana al quale viene attribuito il sermone De psalmodiae bono: "Il diacono a voce chiara, a guisa di recitativo (ad modum praeconii), avverte tutti che osservino il pieno accordo (unitas servetur) sia nel pregare, sia nel genuflettere, sia nel salmeggiare, sia nell' ascoltare le lezioni" ${ }^{29}$ Da qui partiva la corsia centrale, solo in due tempi successivi rialzata assieme al pannello per la sede dell'altare, come ha segnalato il Mirabella Roberti in un rilievo di cui diremo.

Anche qui realtà l'impianto ha sapore di primizia e non vi vedrei sviluppi di embrionali sistemazioni adottate in via "sperimentale" nelle aule teodoriane. Viceversa, secondo me, vi si ritrova quella connessione tra presbiterio e altare che inclino a riconoscere nell'organizzazione dei riquadri musivi delle aule teodoriane, mentre del tuto nuova risulta l'introduzione della solea, collegata con un eventuale ambone e con la liturgia della parola o con un'eventuale tavola per le offerte collocata tra la moltitudine dei fedeli e comunque destinata a regolare certi spostamenti nello svolgimento del rito liturgico, come la processione delle offerte e la distribuzione eucaristica.
Va osservato infine che non sono state trovate tracce per la postazione di recinzioni presbiteriali, che pertanto dobbiamo supporre mobili.

Alla seconda metà del secolo IV appartengono ancora le aule primitive di Parenzo e il complesso cultuale di Orsera, oltre ai rimaneggiamenti sul musaico della Teodoriana meridionale di cui si è già fatto cenno.

Alle aule parentine il Mirabella Roberti applicava le stesse argomentazioni svolte per le aule teodoriane e anzi conduceva un unico discorso per stabilire la posizione dell'altare in medio tanto ad Aquileia che a Parenzo, collegando le analogie rilevate fra i tessellati dei due complessi: anche due delle tre aule parallele di Parenzo presentano, quasi alla stessa altezza, un emblema circa a metà della nave e un altro presso la parete orientale (fig. 9). Pertanto nelle due aule parentine (la terza recentemente scoperta a settentrione era adibita a battistero)

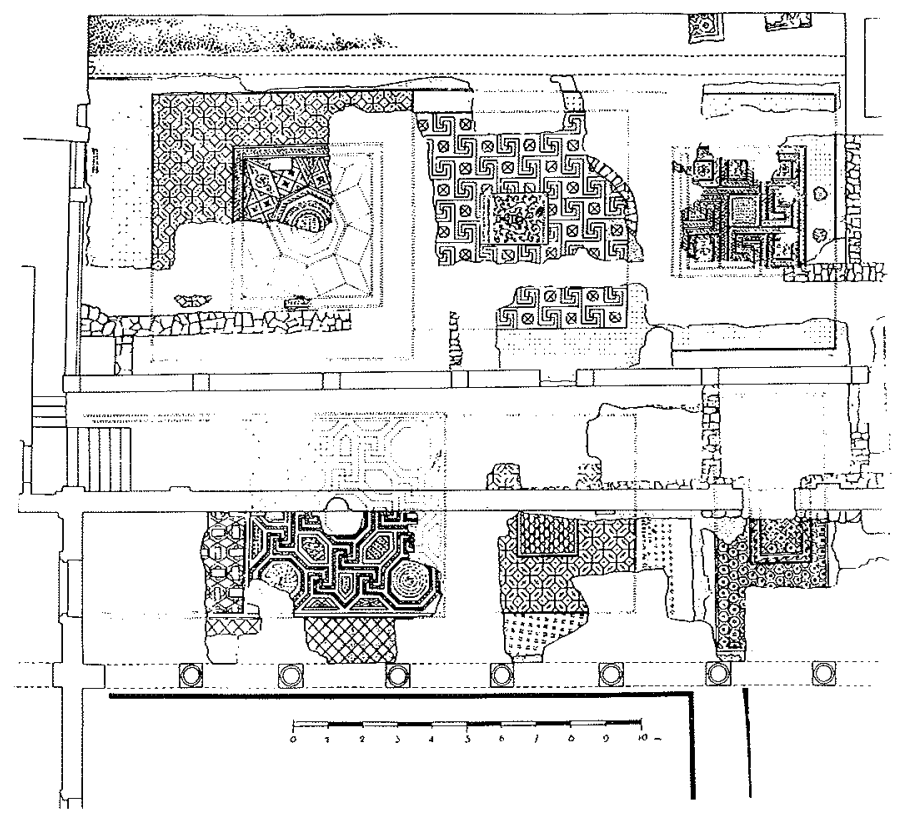

Fig. 9. Poreč, anle primitive (da Molajoli).

l'altare sarebbe stato collocato rispettivamente sul riquadro col vaso fiorito, posto in maestà come simbolo del "premio che i desideri avanza", e sul riquadro con gli archetti fioriti, probabile immagine dei cieli; la cattedra invece sarebbe stata collocata verso il muro orientale e, nell'aula di mezzo (m 20x10), ne resterebbe segno evidente nei quattro rappezzi (fig. 10) provocati dal solito logorio come sulla iscrizione di Teodoro (il supposto fenomeno però non si è verificato nell'aula meridionale di Parenzo); i pesci successivamente inseriti nel pannello musivo a meandri (quello che poteva forse appartenere ancora a un ambiente della domus romana) confermerebbero l'ipotesi che riconosce a quel sito la sede della cattedra e del clero; infatti il Mirabella Roberti rilevava che la sede dei presbiteri nei musaici è spesso distinta con pesci o con scene marine, quasi a monito della loro missione, come nel catecumeneo di Orsera, nella campata orientale della Teodoriana Sud e nel riquadro a "onda subacquea" della meridionale di Parenzo. ${ }^{30}$ Qui sono state ritrovate, fra il terzo e il qarto settore musivo, le fondazioni di un muro trasversale, probabile sostegno a una recinzione di plutei o di transene; la distinzione tra queste due parti dell'aula sembrerebbe confermata anche dal fatto che la zona orientale presenta il piano del suo 


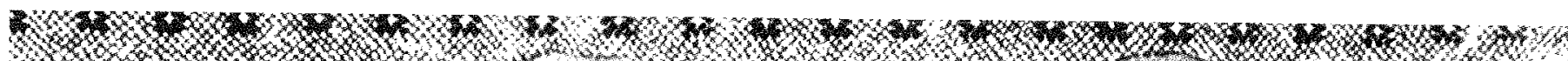

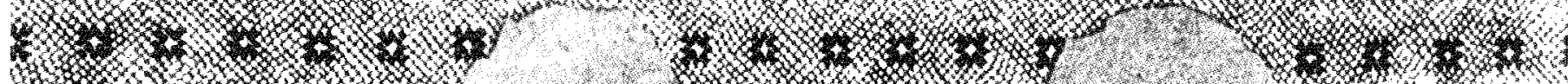

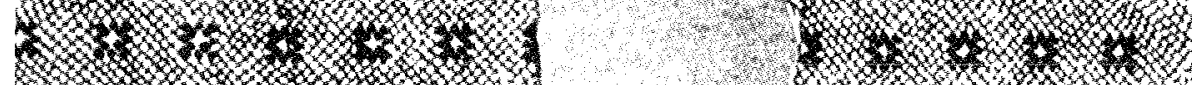
W

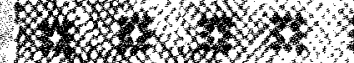

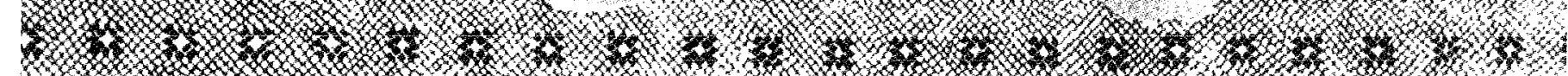

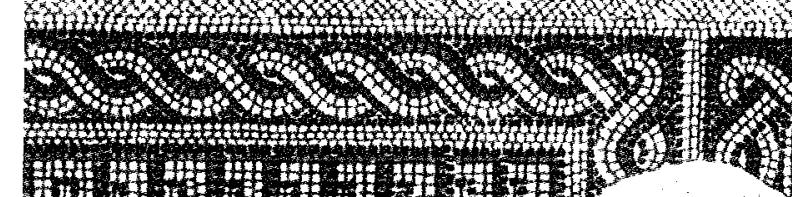
(2) H. 1+17)

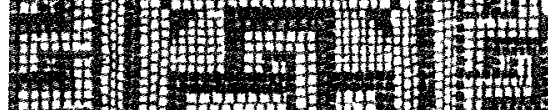

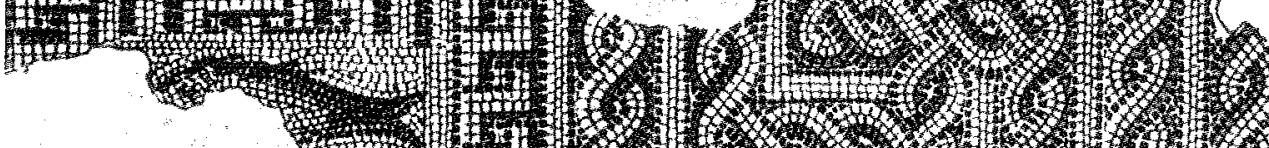

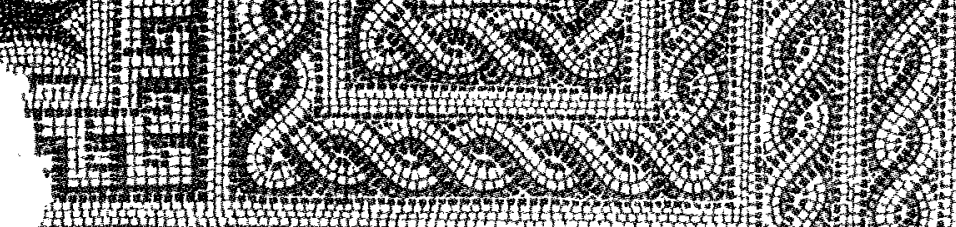

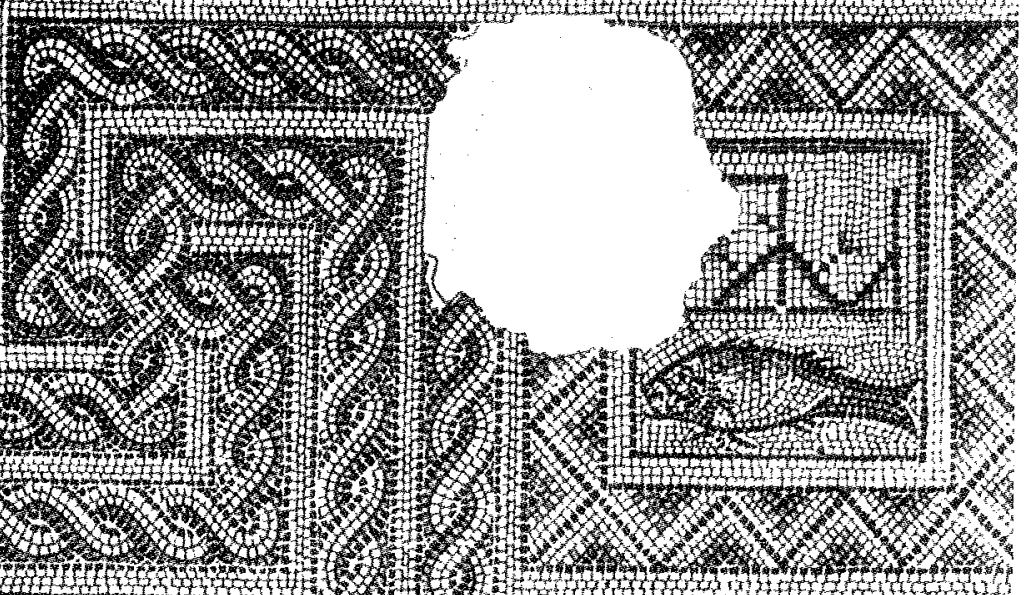
(1)
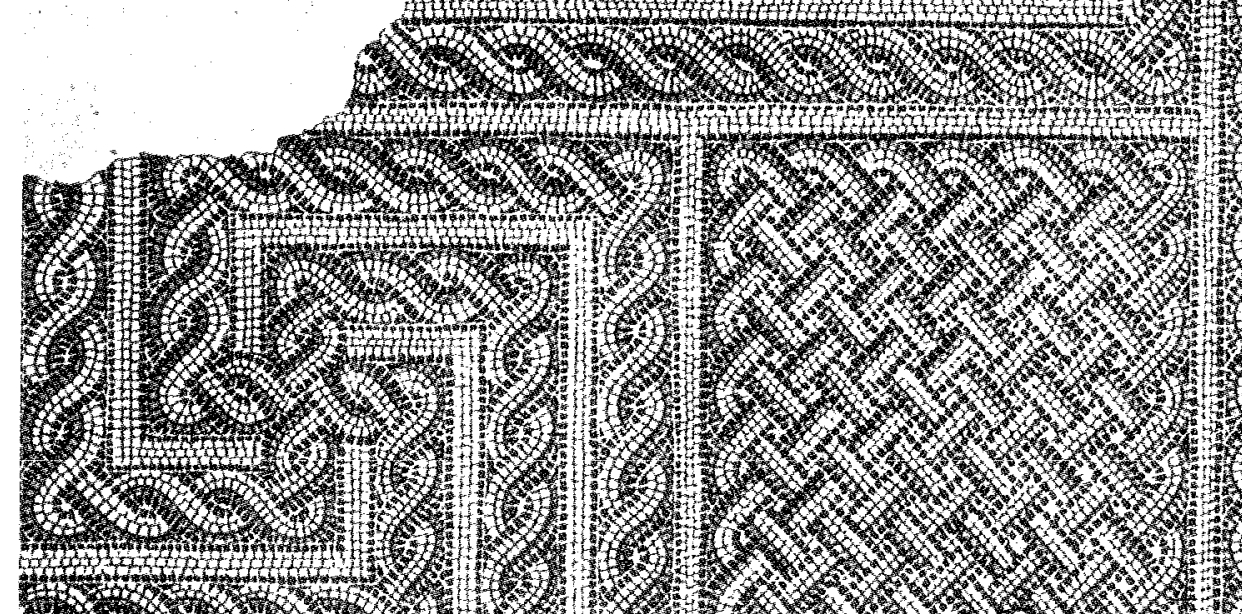
W

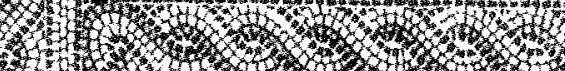
$16+3 \times$

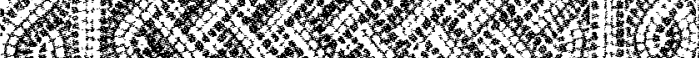

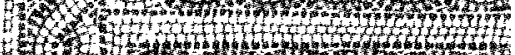
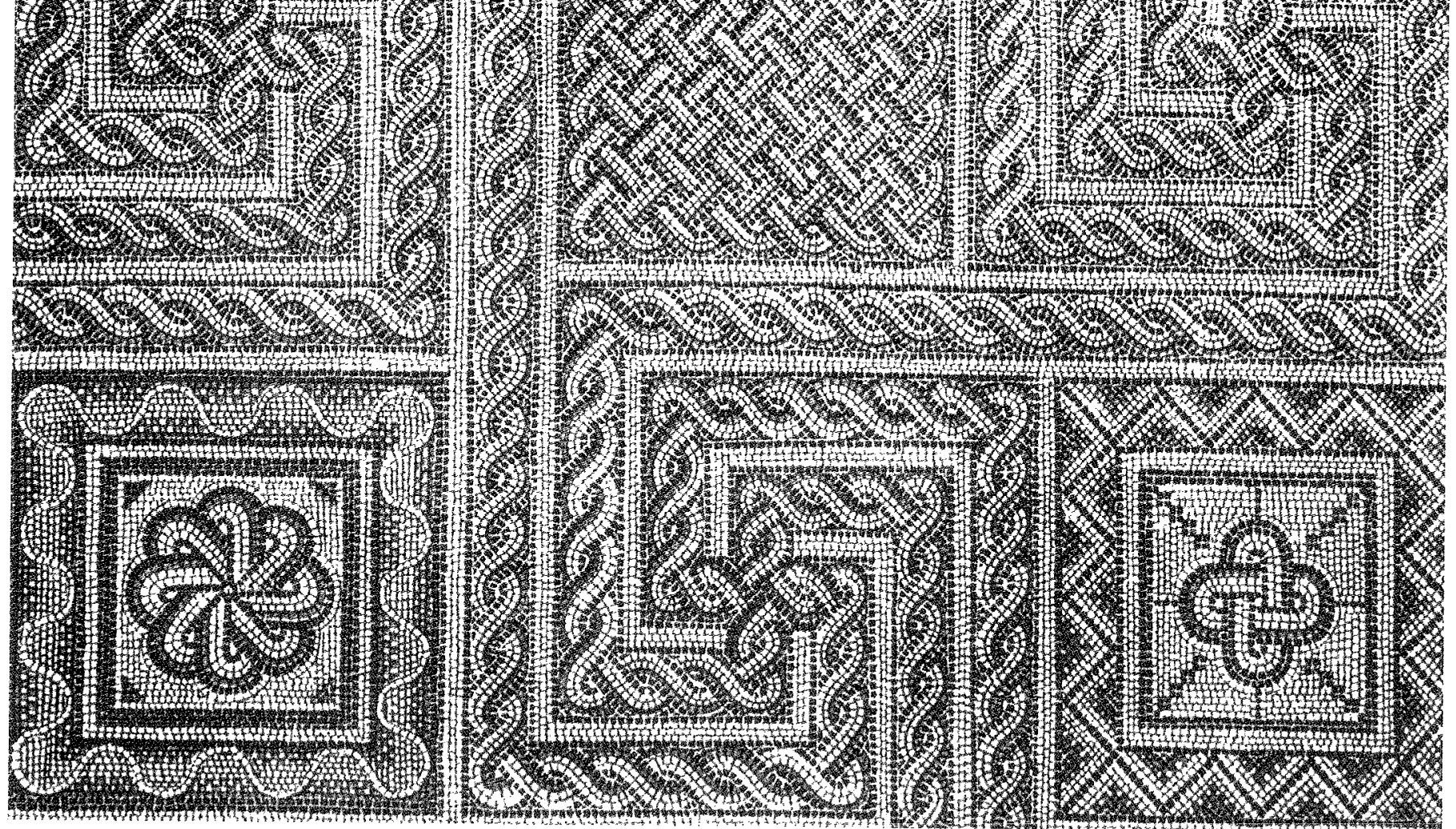
pavimento musivo a un livello di $\mathrm{cm} 5$ più alto rispetto a quello degli altri tre pannelli. Resta tuttavia discussa la funzione liturgica dell'aula come pure la presenza o meno di un altare. Nell'aula intermedia invece manca ogni traccia di recinzione presbiteriale o un segno qualsiasi di struttura per poter avvalorare un'ipotesi invece di un'altra, mentre gli emblemata al centro dei tre tappeti musivi rientrano nell'uso della decorazione ellenistico-romana tutt'al più con un arrichimento di significati simbolici. Una cosa sola è certa, che, se i quattro rappezzi sul tappeto orientale fossero gli ultimi residui di una mensa d'altare, non ci sarebbe posto per la cattedra ad Est e gli stessi movimenti del celebrante rivolto al popolo non sarebbero stati agevoli proprio per mancanza di spazio. Ma pur accettando i'ipotesi del Mirabella Roberti incline a riconoscere in quei rappezzi i segni di una cattedra anziché di un altare, mi sembra che, per quanto detto sopra, dovremmo supporre l'uso di transenne mobili destinate a recingere entro un'unica area cattedra e altare, a meno di non immaginare un caso che non prevedesse separazioni di sorta e lasciasse la celebrazione del rito a uno spontaneismo liturgico praticabile nei piccoli gruppi e nelle giovani comunità. In tal caso allora la mensa avrebbe potuto essere disposta anche sopra il riquadro con il vaso fiorito, ma che questo sia stato voluto come sede dell' altare non lo affermerei sia per la forma dell' emblema (m 2x1,59), più lungo che largo e quindi contrario alla normale forma dell'altare ${ }^{31}$ sia per l'epigrafe dei generosi donatori, Lupicinus et Pascasia, che, avendo offerto più di 500 piedi, hanno tenuto a distinguersi con un pannello singolare, secondo la tradizione del musaico ellenistico solito a rompere la monotonia disegnativa di un unico elemento decorativo con l'inserimento di un emblema centrale.

Diversa invece è l'articolazione degli scomparti musivi operata nel catecumeneo di Orsera datato alla seconda metà del secolo IV; esso è diviso in due zone: una (m 4,68x1,29) raffigura pesci natanti, l'altra (m 4,68x4,72) è formata da quadrilateri curvinitiei connessi fra loro. Concordo col Mirabella Roberti quando afferma che la caratteristica partizione della superficie dell'aula e la rappresentazione dei pesci in una zona ben definita, oltre a testimoniare uno stretto parallelismo con la Teodoriana meridionale di Aquileia, sono connesse con una destinazione liturgica della sala. Anche la Farioli, interes- satasi alle tematiche musive relative alla zona sacra, sottolineava l'innegabile interdipendenza tra iconografia e collocazione, che sugerisce ai fedeli riposti sensi simbolici.

Se quest'aula è, come sembra certo, un catecumeneo, Orsera ci offre il primo esempio di un ambiente destinato all'istruzione dei catecumeni in un centro non episcopale e contribuisce a determinarne gli aspetti costruttivi e liturgici. La sistemazione interna doveva richiedere uno spazio destinato ai catecumeni e uno ai sacerdoti docenti: questi dovevano occupare il riquadro dei pesci, ricco di valore simbolico prima che ornamentale, quelli l'area maggiore ornata a musaico geometrico da dove, ascoltando, potevano aver presente lo squarcio del simbolico mare. ${ }^{32}$

\section{IL PROBLEMA DELLA SOLEA}

Connesso col problema del presbiterio e dell'altare è - come si è visto - quello della solea, che costituisce uno sviluppo del bema in lunghezza sull'asse della navata maggiore in numerose basiliche del mondo cristiano antico.

Un'indagine sistematica condotta dallo Xydis nel 1947.33 non poca luce aveva gettato su tale questione, essendo egli riuscito a distinguere con chiarezza tre tipi principali di questa struttura in possesso di tutte o solo di alcune caratteristiche della solea di S. Sofia di Costantinopoli, descritta da Paolo Silenziario nel secolo VI: ${ }^{34}$

1) un tipo lungo e stretto, con o senza ambone all'estremità occidentale, non più largo dell'entrata del presbiterio e chiuso da plutei, come a Efeso (fig. 11), in Crimea, a S. Menas in Egitto, a Salona (figg. 12-13) - possiamo ora aggiungere noi a quasi cinquant'anni di distanza - in basiliche padane, altoadriatiche e alpine;

2) un tipo accorciato, unito alla porta principale del presbiterio, non più largo della stessa e talvolta dotato di colonne, come in Grecia, nei Balcani e in esempi dell'Africa settentrionale;

3) un tipo largo, facilmente assimilabile alle strutture del primo gruppo, come nella basilica superiore e forse anche in

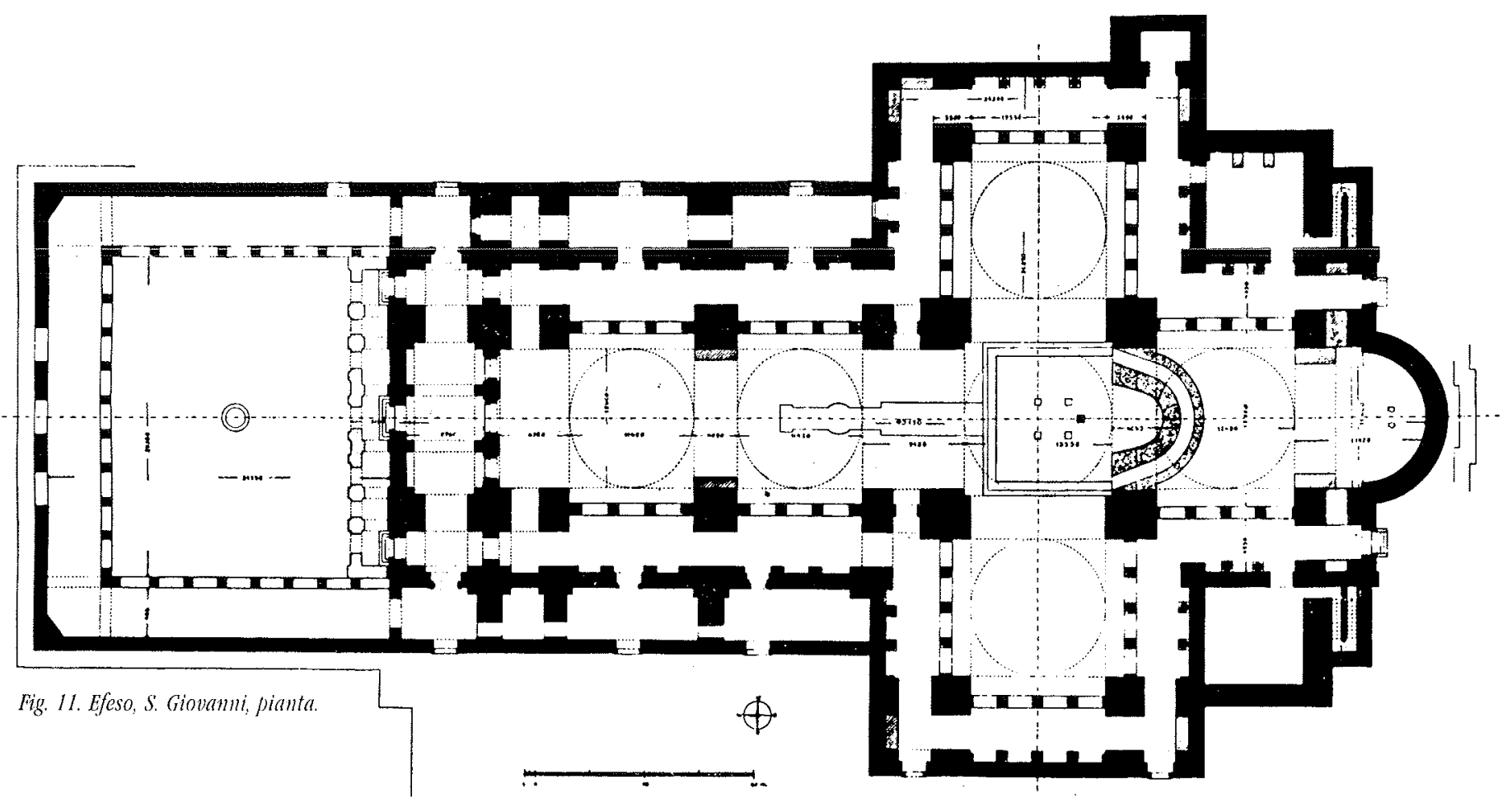




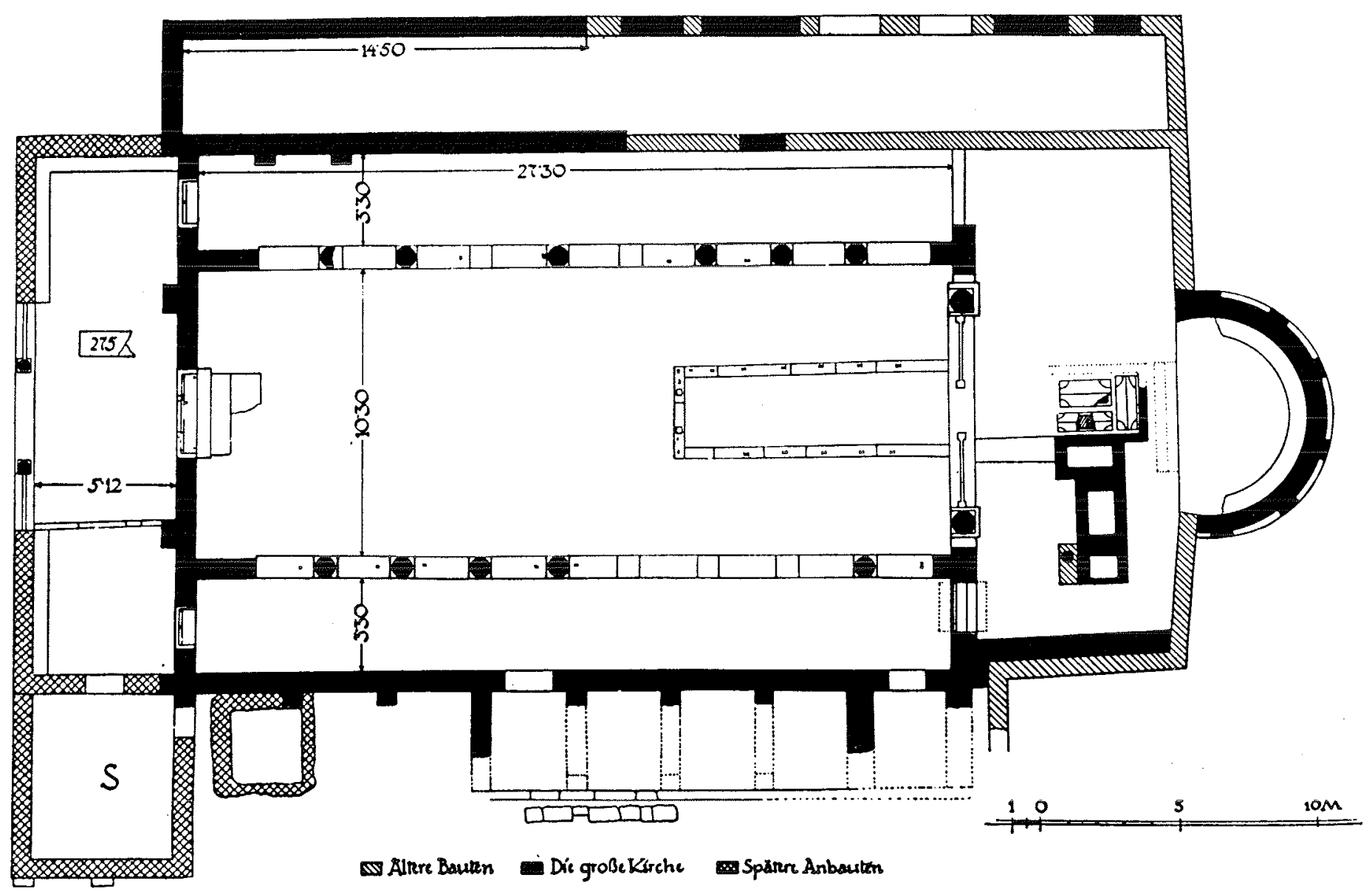

Fig. 12. Salona, basilica cemeteriale di Manastirine, pianta.

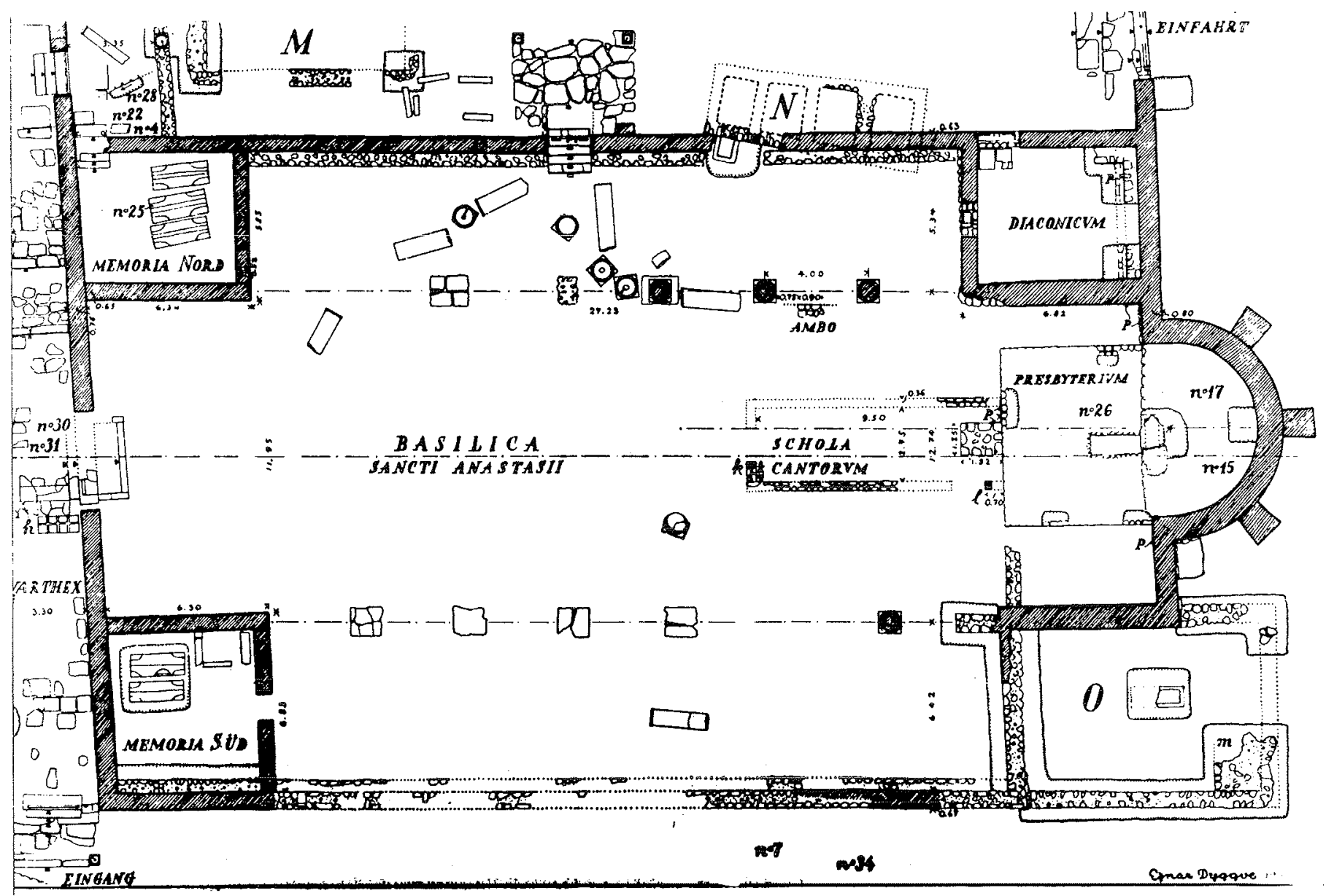

Fig. 13. Salona, basilica cemeteriale di Marusinac, pianta dello scavo 


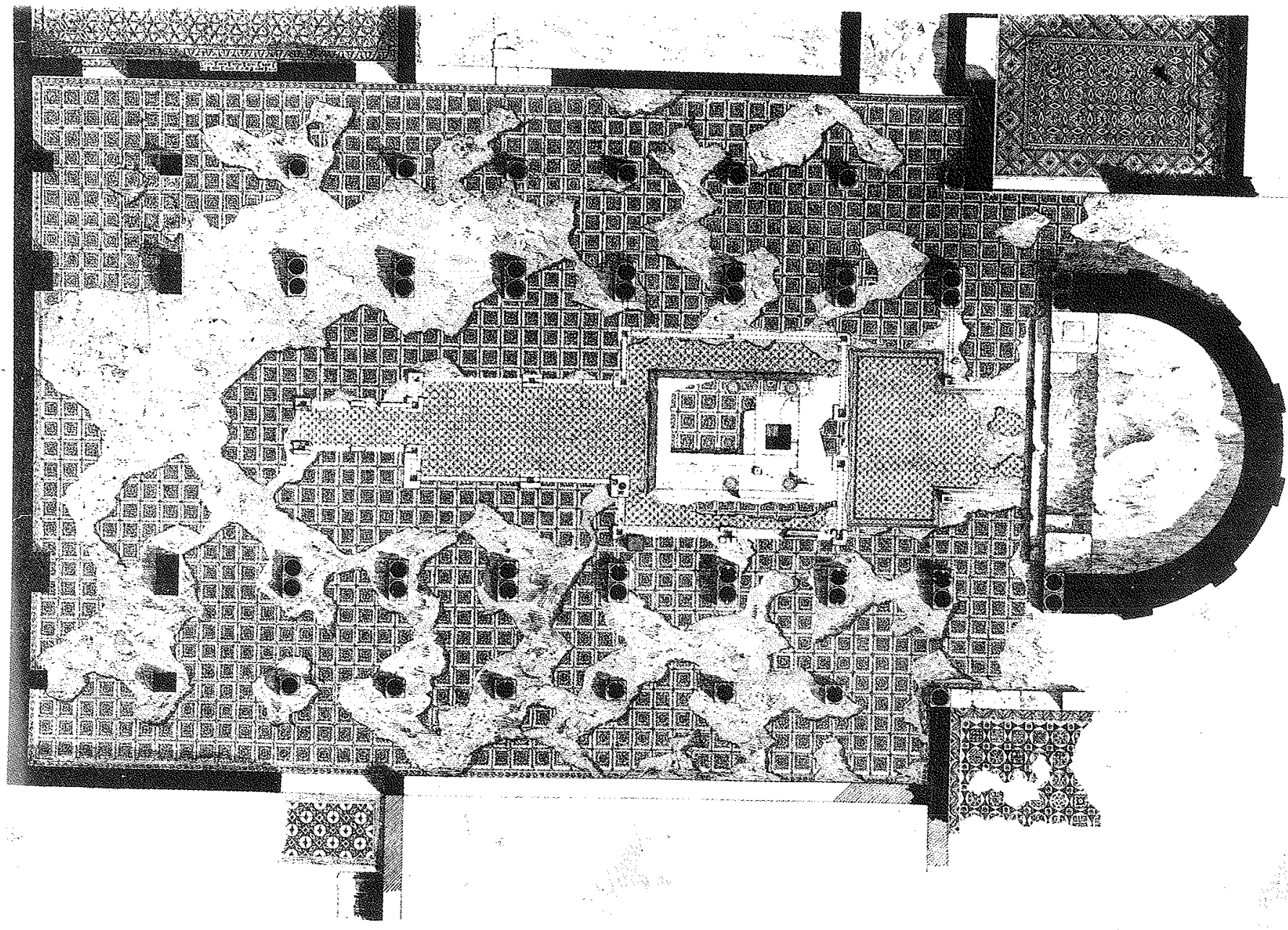

Fig. 14. Dermesch, basilica, pianta.

quella inferiore di S. Clemente a Roma e nella basilica africana di Dermesch (fig. 14) in unione a un passaggio lungo e stretto, del primo tipo, verso occidente.

Se la larghezza del terzo tipo fa pensare alla funzione di contenere i cantori e il secondo tipo può essere sentito come un rilievo all'entrata del presbiterio, soprattutto il primo tipo appare interessante: questa solea lunga e stretta infatti sembra suggerire l'idea di un movimento da e verso l'altare e accentua il carattere processionale della basilica cristiana; in parecchi casi essa era unita all'ambone, così che possiamo raffigurarci la scena, descritta con religioso stupore da Paolo Silenziario, quando:

"Colui che annunciò la buona novella ritorna sui passi suoi su in alto levando quel codice d'oro, mentre la folla onorando quel Dio immacolato si spinge per baciare e posare le palme sui libri divini; ma a la ringhiera intorno del popolo l'onda si frange" (trad. Veniero).

Sulla base delle conoscenze possedute in merito alla distribuzione cronologica e geografica della solea del primo tipo, lo Xydis poteva concludere che l'apprestamento architettonico-liturgico comprendente presbiterio, solea, ambone, pur rappresentando una sintesi di strutture preesistenti e variamente documentate nel mondo cristiano antico, aveva avuto origine a Constantinopoli nel secolo VI e che la sua presenza in altre regioni doveva essere considerata in stretta connessione con gli usi liturgici e con le attività edilizie di Giustiniano, al momento in cui si andavano affermando speciali sviluppi liturgici con le cerimonie delle Piccole e delle Grandi Entrate ${ }^{35}$ Nel mondo latino, conforme a differenti necessità della liturgia occidentale, la solea sarebbe stata usata invece come recinzione per il coro dei cantori, così da venir indicata col nome di schola cantorum.

Ma sebbene l'accurata analisi dello Xydis fosse condotta con tanto rigore metodologico, con tanta aderenza alle fonti e ai resti archeologici da far pensare, a tutta prima, che il problema della solea sia stato risolto, un'aggiornata rassegna delle nuove scoperte archeologiche al riguardo e la particolare attenzione a quanto indagini anche recenti son venute precisando ad Aquileia stessa e in altri centri padani come a Milano (fig. 15) e a Verona (figg. 16-16a), avevano riproposto una nuova impostazione del problema ${ }^{36}$ che andrebbe ripresa in esame globalmente dopo le ultime scoperte di Ravenna (fig. 17), ${ }^{37}$ di Aosta (fig. 18) di Ginevra. ${ }^{38}$

Infatti se questo apprestamento liturgico può essere da noi un portato del secolo VI, come a nel Duomo di Pola, dove la solea è sicuramente immessa durante il secolo VI nel pavimento del secolo V, ${ }^{39}$ in $\mathrm{S}$. Eufemia di Grado, dove è stata scavata dal Mirabella Roberti e segnata sul livello dal pavimento eliano del 579., ${ }^{40}$ è pur vero che la troviamo nelle Postteodoriane e nella basilica del fondo Tullio alla Beligna di Aquileia (fig. 19), ${ }^{41}$ a Concordia ${ }^{42}$ nella basilica di Piazza della Corte a Grado sovrapposta a un pavimento musivo ritenuto della fine de IV o dell'inizio del V secolo (figg. $20-21)^{43}$ e a Invillino in Carnia ${ }^{44}$ per restare in ambito aquileiese: tutte certamente anteriori al secolo VI, anche se non si possono fissare datazioni precise.

Permangono dunque seri dati di fatto che contraddicono la tesi dello Xydis o, quanto meno, ne indicano i limiti; infatti 
MLLANO - Piazs mo Drowo

Bastica pultocristinin of StECLA

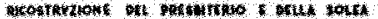

buas?

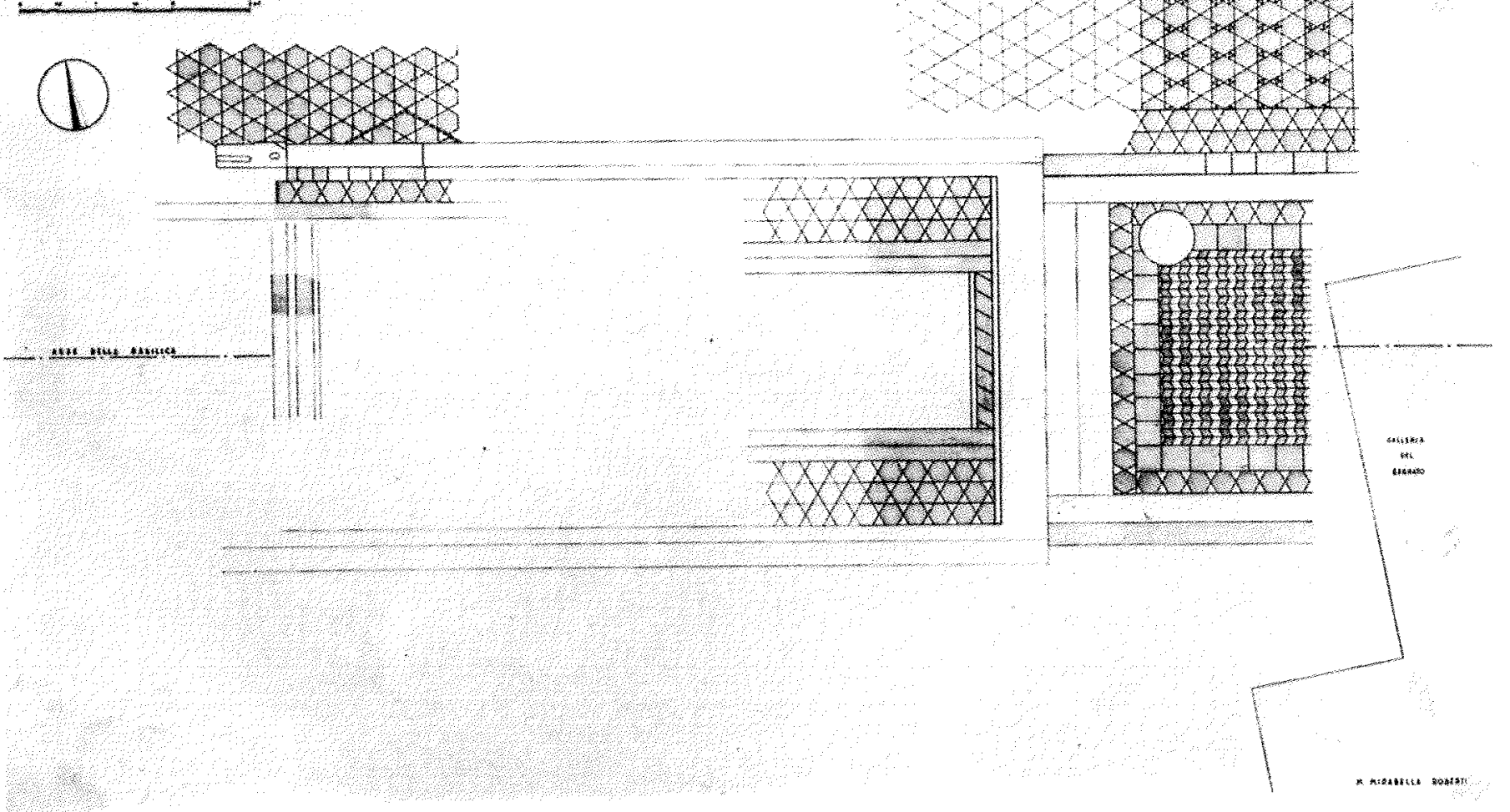

Fig. 15. Milano, S. Tecla, ricostruzione della solea (dal Mirabella-Roberti).

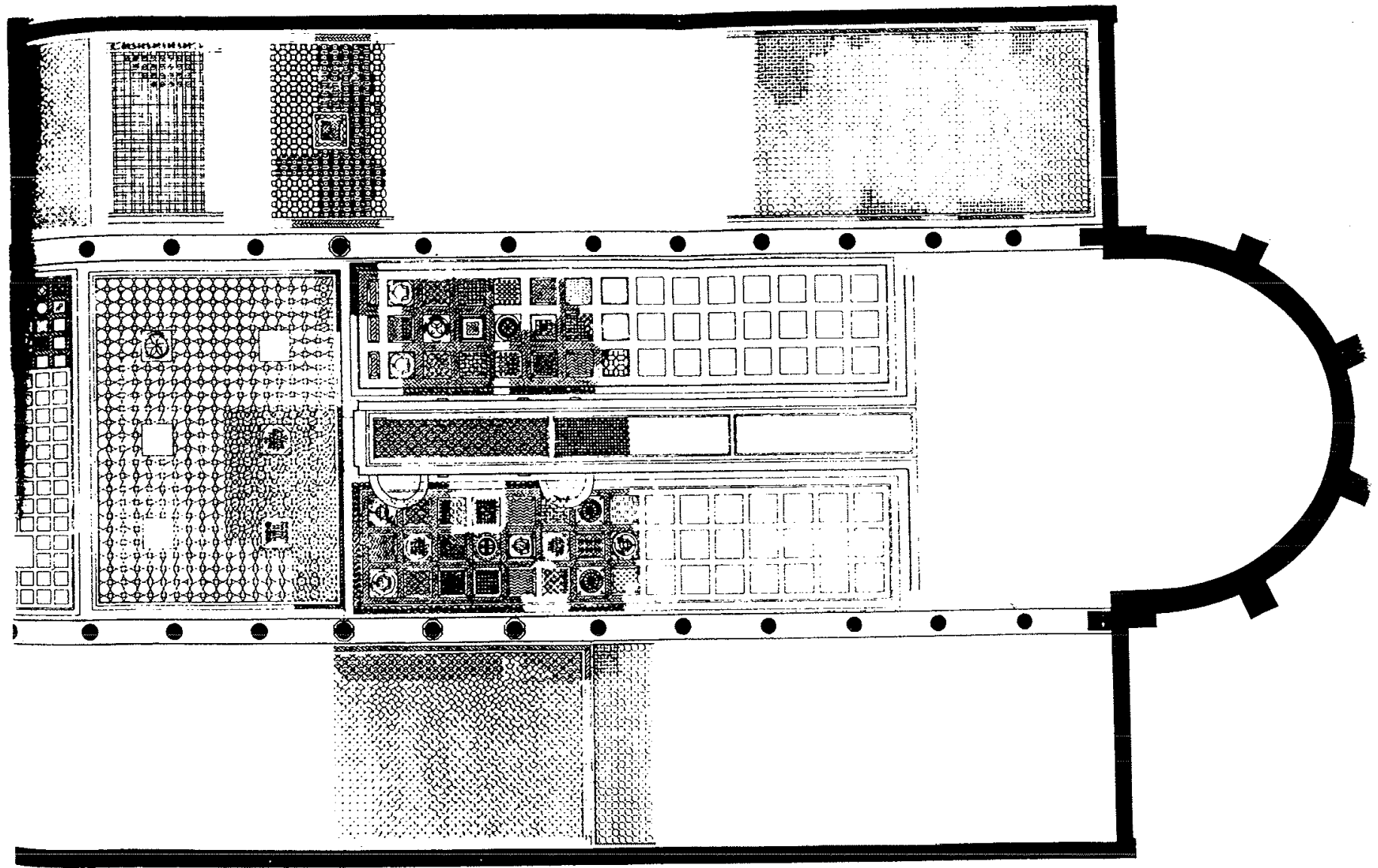

Fig. 16. Verona, cattedrale paleocristiana, pianta 


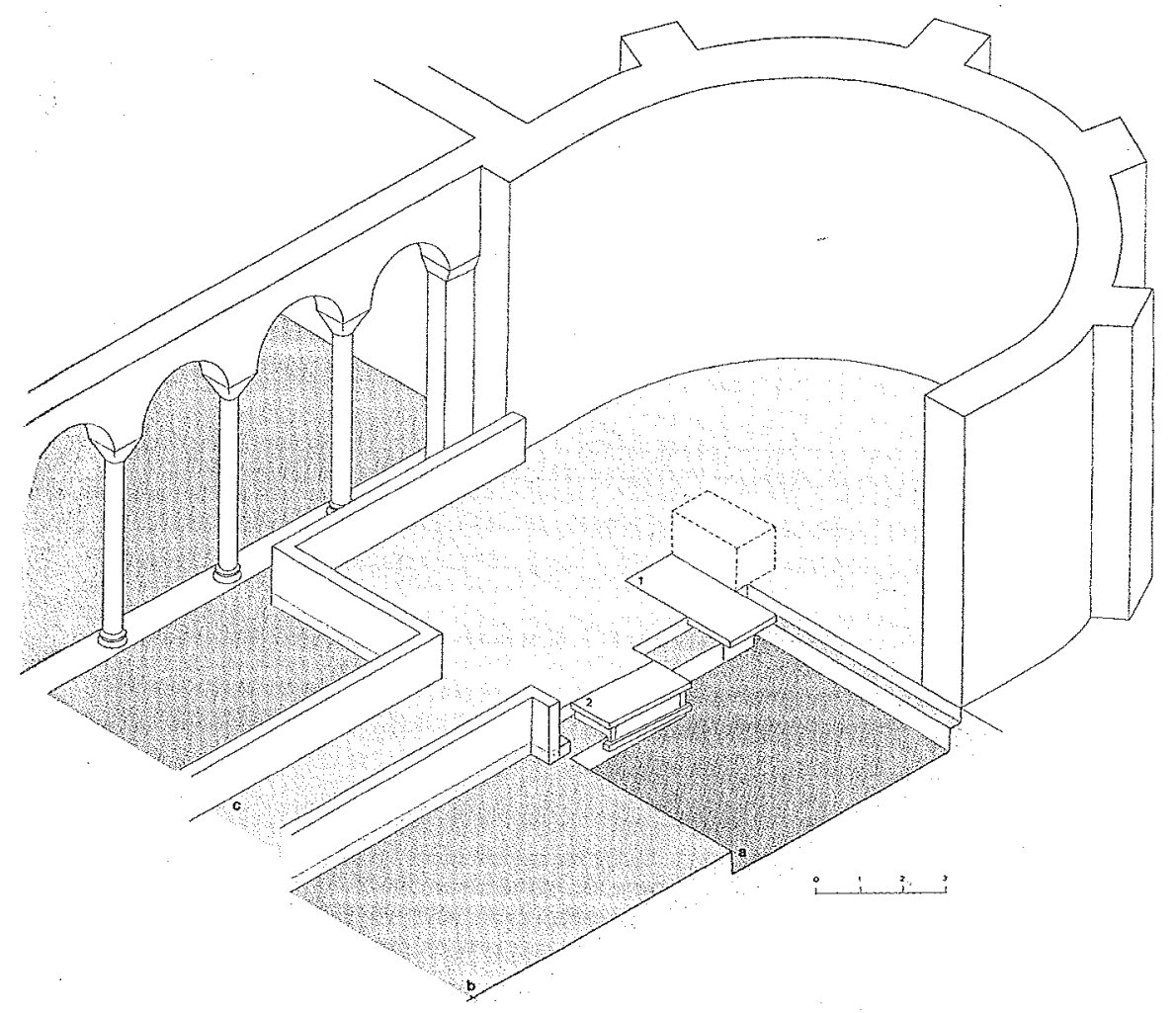

Fig. 16a. Verona, cattedrale paleocristiana, ricostruzione della solea.

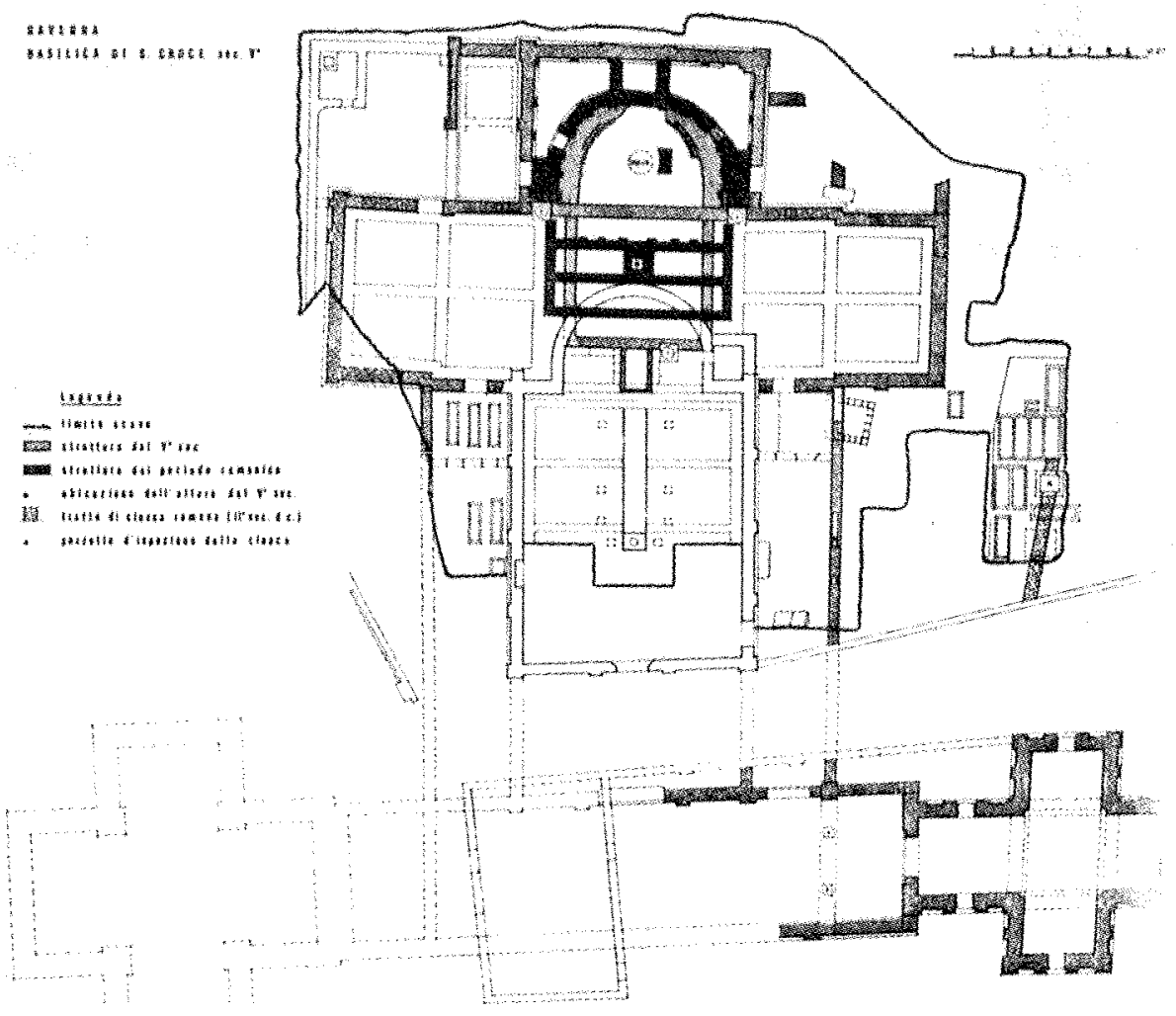

Fig. 17. Ravenna, S. Croce, pianta. 


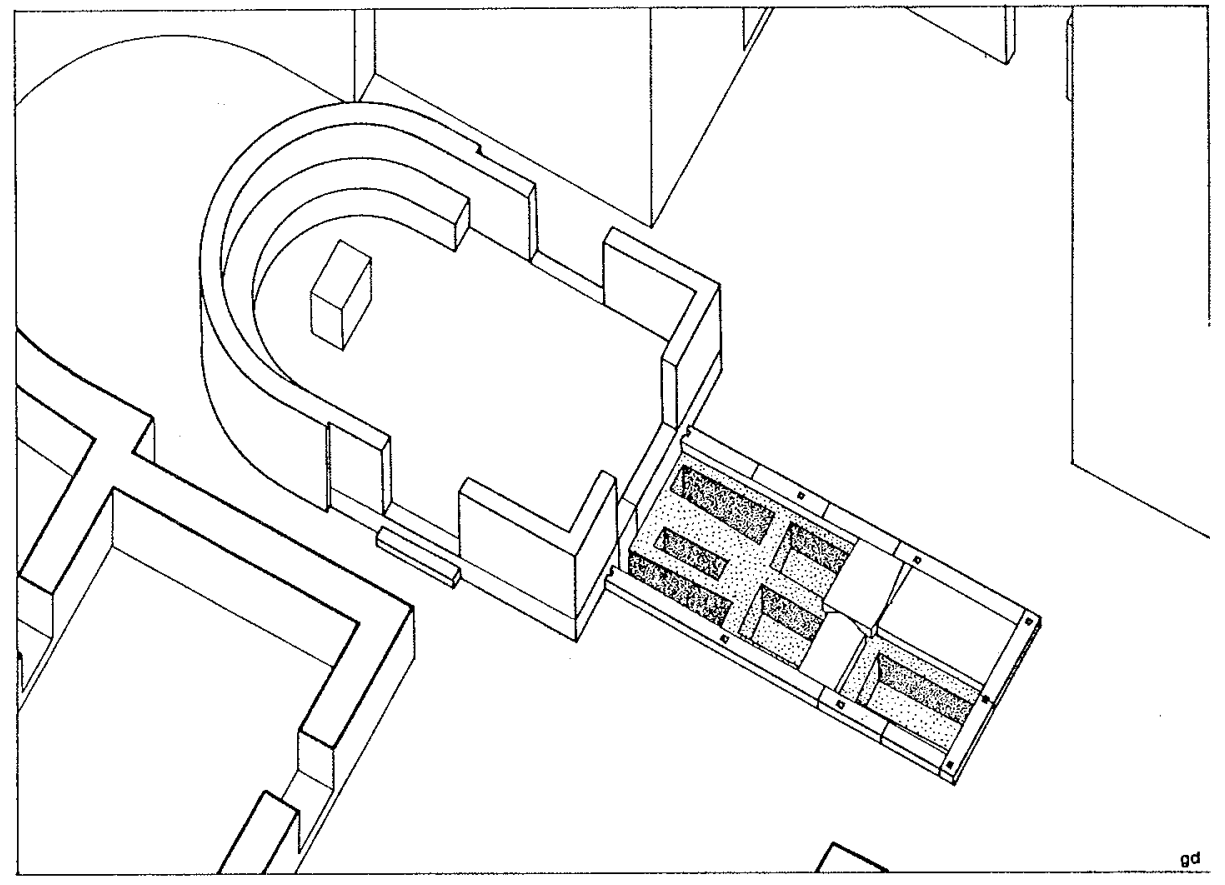

Fig. 18. Aosta, solea di S. Lorenzo (da J.F. Reynaud).

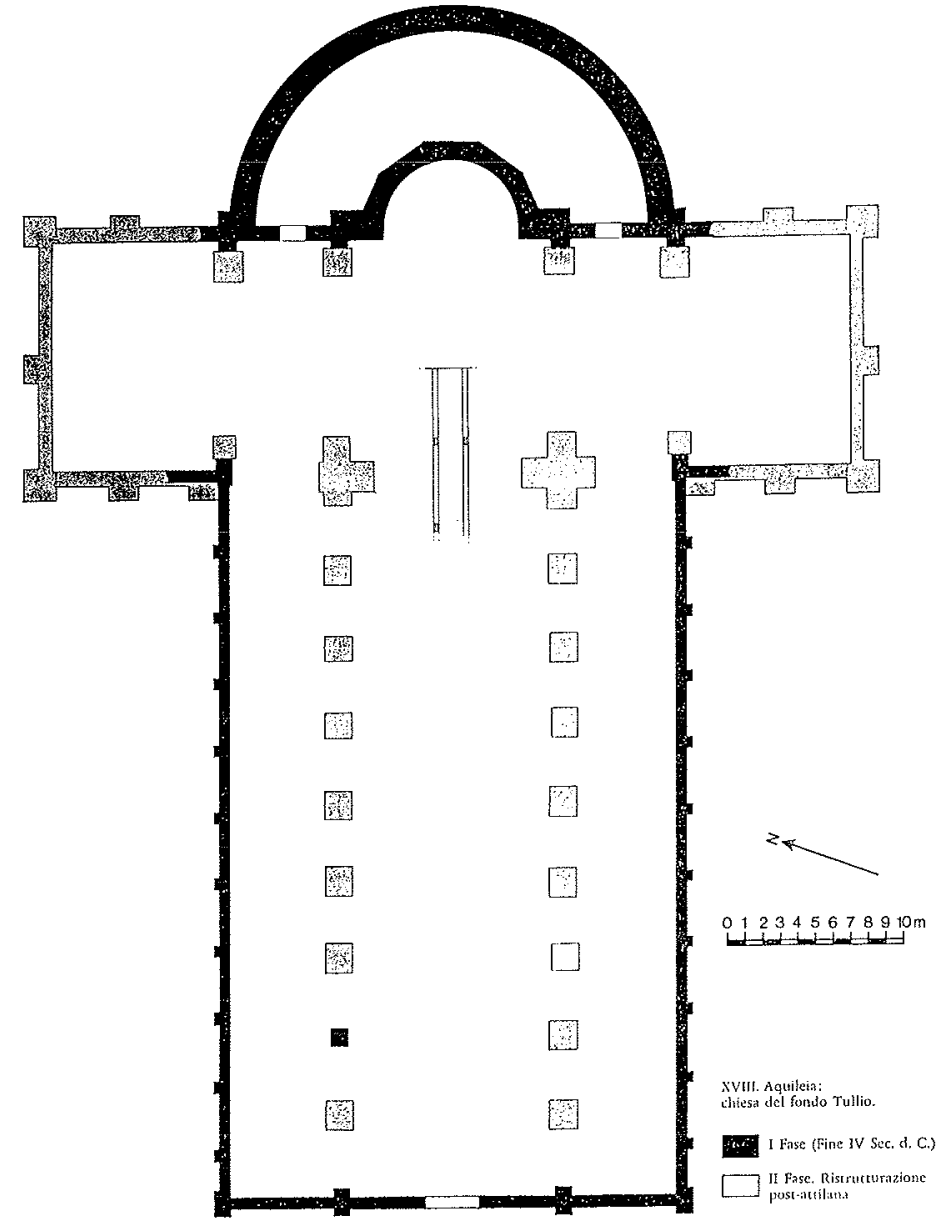

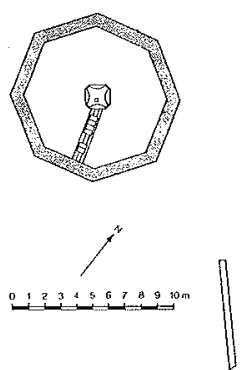

Grado:
chiesa di plazza delia Cortc, I lasc.
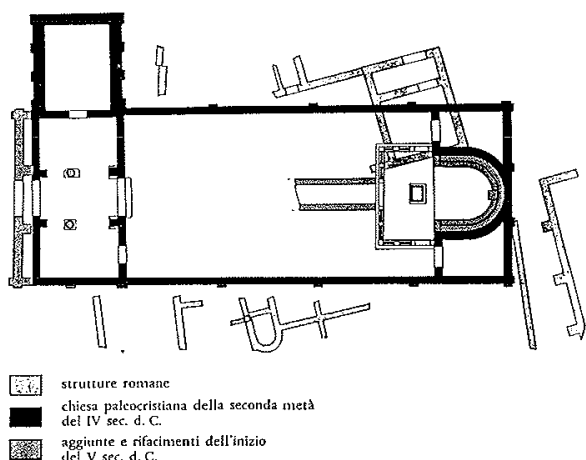

Fig. 20. Grado, chiesa di Piazza della Corte, I fase (da Bertacchi)

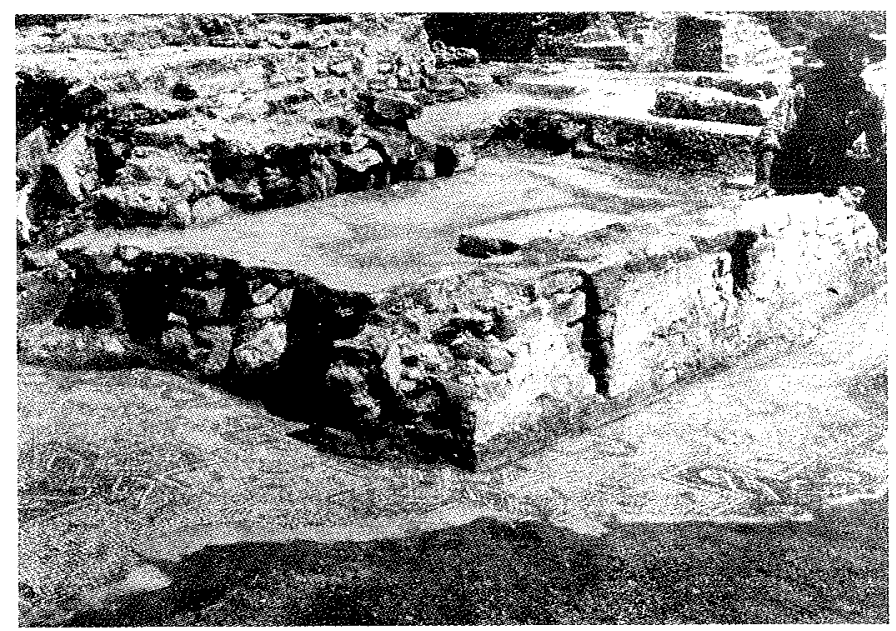

Fig. 21. Grado, chiesa di Piazza della Corte, resto della solea scavata da Swoboda e Wilberg. 
queste crescenti digitazioni del presbiterio lungo l'asse della navata centrale sono presenti qui da noi, in un'epoca in cui non possono venir giustificate come un'influenza delle attività edilizie e degli usi liturgici di Costantinopoli. La forma di questa struttura esistente già alla fine del IV secolo o al principio del $\mathrm{V}$ non può infatti essere messa in relazione con lo sviluppo delle cerimonie delle Entrate, diffusesi nella liturgia orientale durante i primi tempi del secolo VI. Per quel che sappiamo, invece, possiamo concordare con lo Xydis, quando pensa che a Costantinopoli sia avvenuta la sintesi di quelle forme già esistenti in varie regioni del mondo cristiano antico, come quella specie di breve portico innanzi al santuario documentato in basiliche della Grecia e dei Balcani, oltre che in un pannello del ricordato cofanetto di Pola ${ }^{45}$ e nella prima fase della basilica di Concordia; ${ }^{46}$ quella congiunzione dell ambone al cancello, attestata nel $\mathrm{V}$ secolo anche a Lavant nel Norico (fig. 22) ${ }^{47}$ nel battistero e nella basilica meridionale di Ginevra (fig. 23) ${ }^{48}$ oltre che a Gerasa in Siria; ${ }^{49}$ e infine le lunghe solee di Aquileia, di Concordia, di Milano, di Verona, di Aosta, di Invillino e di Ravenna che lo Xydis non conosceva o non poteva ancora conoscere quando redigeva il suo studio nel 1947.

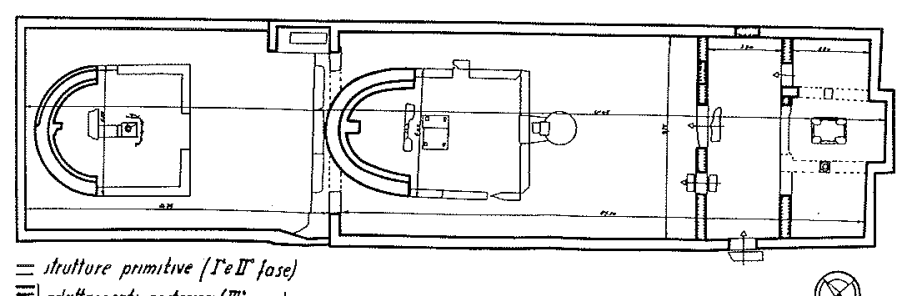

Eladatament' postersorr ( $\mathbb{H}^{\circ}$.)

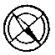

Fig. 22. Lavant, pianta della chiesa.

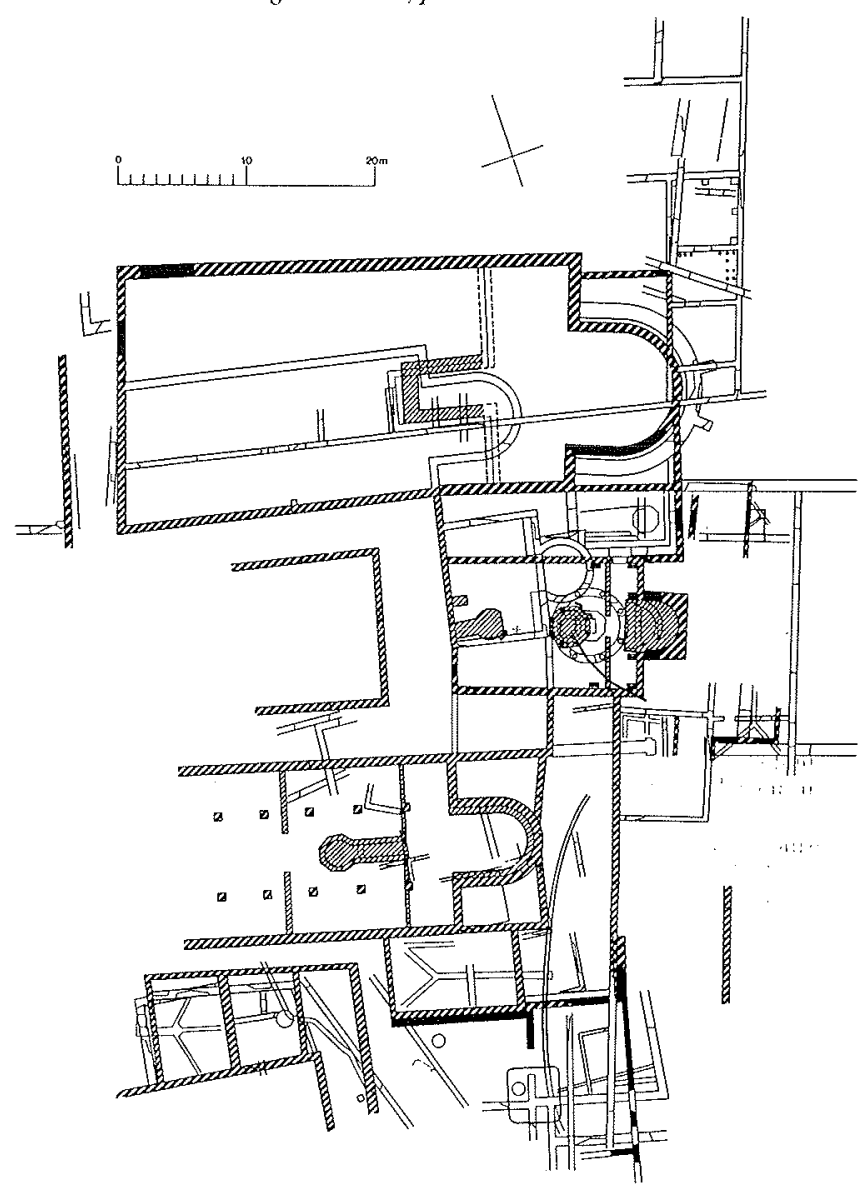

Fig. 23. Ginewa, catedrale, pianta (da Bonnet).
Per quanto riguarda le origini della solea dunque, mi era già sembrato opportuno porre l'attenzione su queste nostre prime testimonianze e servirsi delle fonti e dei resti di epoca bizantina solo per considerare quali fossero stati i successivi sviluppi di una struttura già documentata per epoche precedenti, nel tentativo di lumeggiare il momento più antico e più oscuro della sua origine attraverso lo studio di una fase successiva più evoluta e generosa di notizie. Quanto alla funzione liturgica, avevo già espresso l'opinione che la solea delle nostre basiliche fosse adibita allo svolgimento della parte didattica della Messa, per la quale in Siria - com'è noto - era destinato l'ambone-esedra e con esso gran parte della navata centrale. Avevo supposto perciò che la cerimonia liturgica dovesse venir ripartita tra il santuario e l'ambone o la solea, con delle processioni del clero alle quali veniva attribuito, conforme alla sensibilità dell'epoca e alle esigenze pastorali della liturgia, anche un valore simbolico. ${ }^{50}$ Tuttavia non escluderei che, a prescindere dal simbolismo e dai probabili influssi siriaci più sensibili in certe zone, anche altre esigenze in relazione all'ordinamento estemo ed alla funzionalità del rito abbiano favorito e incoraggiato la costruzione della solea, destinata a segnare una netta separazione tra clero e popolo e qundi tra navata e coro di cui è un prolungamento, come sembra attestare anche un distico forse proveniente da una basilica di Siviglia e databile intorno al sec. VI, noto purtroppo solo attraverso l'Anthologia Hispana del sec. VIII: Sola ministeriis via competit ista supernis I dum populos sacris segregat ipsa choris. ${ }^{51}$

Purtroppo, mentre numerose ricerche sono state avviate per stabilire il testo dalla Messa primitiva, solo tentativi casuali e incerti sono stati fatti per ricostruire i riti esterni e le rubriche della sinassi. Cio nonostante già il Mathews, nel suo studio sulla sistemazione e sulle funzioni liturgiche del coro nelle primitive basiliche romane, ${ }^{52}$ ha ritenuto possibile individuare, sulla base dell'Ordo Romanus I (generalmente accettato come la descrizione della Messa stazionale nel secolo VI a Roma), quei momenti della Messa e i relativi spostamenti spaziali degli officianti che più fossero in grado di spiegare la solea, messa in luce dagli scavi anche nelle basiliche romane di S. Pietro in Vincoli (439-440), ${ }^{53}$ di S. Stefano sulla via Latina $(440-460),{ }^{54} \mathrm{di}$ S. Clemente (533-535), ${ }^{55}$ di S. Marco $(550-650)^{56}$ e di S. Maria Antiqua (772-795) ${ }^{57}$ Questi momenti potevano essere la cerimonia dell'ingresso e dell'uscita del pontefice, la lettura delle sacre scritture, la processione dell'offertorio e quella della comunione. Noi non possiamo riferire in blocco le ipotesi e le conclusioni del Mathews alla solea di Aquileia, di Concordia, di Invillino, di Ravenna, di Milano, di Verona, di Aosta e di Ginevra, perché le rubriche dell' Ordo Romanus I rifletorno una liturgia più tarda e propria dell'ambiente romano, ma una cosa è certa: che quei momenti della cerimonia liturgica dovevano essere tali da richiedere sempre e dovunque degli apprestamenti particolari per una regia, ordinata con dignità e decoro, della cerimonia liturgica.

Vent'anni or sono il problema era stato ripreso dal De Angelis d'Ossat piu su citato, che aveva creduto di poter riconoscere nella lunga solea l'attrezzatura ideale per la distribuzione eucaristica al popolo, così da ridurre al minimo gli spostamenti dei fedeli.

\section{GLI ESEMPI DELLE BASILICHE ALTOADRIATICHE}

Qesta lunga digressione sull'origine e sulla funzione della solea non è senza ragione quando si pensi che essa definisce uno spazio a indubbia destinazione liturgica, in quanto sopraelevato rispetto al suolo o distinto dai segni di una recin- 


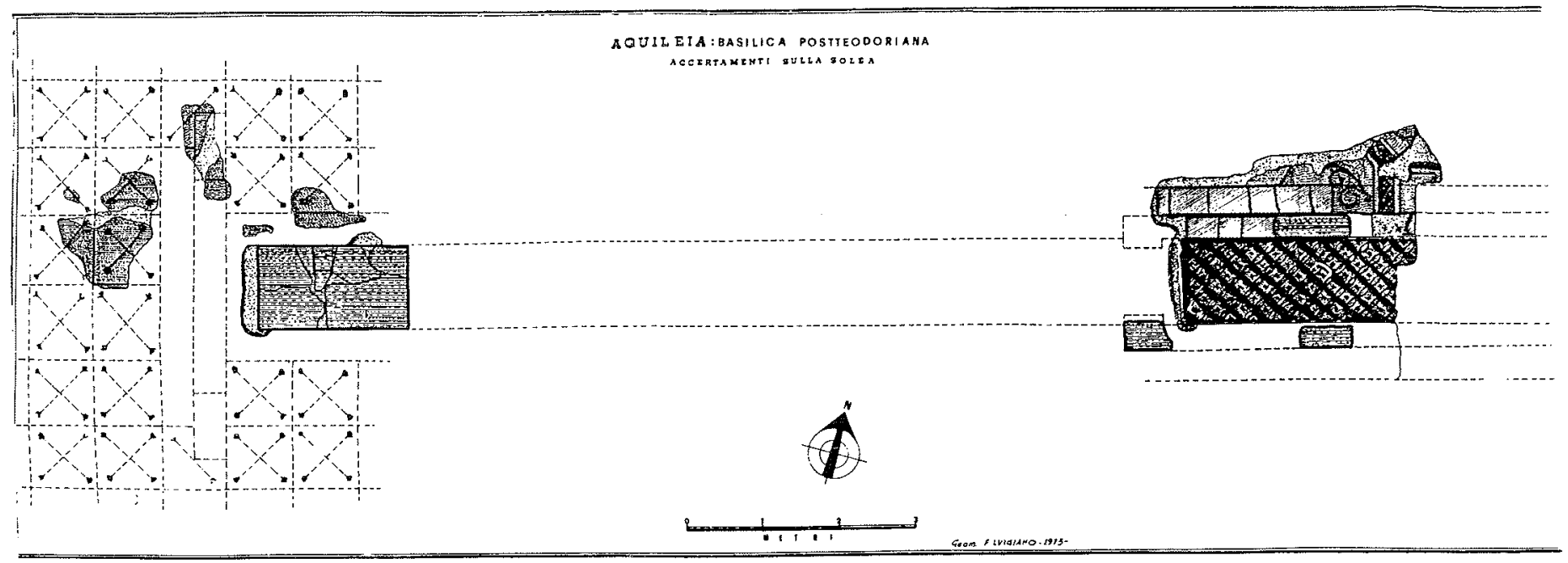

Fig. 24. Aquileia, solea della postteodoriana nord.

zione ormai perduta. Anche a questo riguardo sono significative le scoperte recentemente fatte dalla Bartacchi nella Postteodoriana settentrionale di Aquileia, su cui vale la pena soffermarsi brevemente.

Qui si è potuto appurare che la basilica non era fornita sin dall'inizio di una vera e propria solea, ma soltanto di una corsia segnata sul pavimento, come aveva già intravisto il Brusin. Questa doveva terminare a occidente con la piattaforma di lastre di pietra $(\mathrm{m} 2 \times 1,15)$ scoperta nell'interno del campanile a livello del musaico circostante (fig. 24); la forma allungata da Est ad Ovest rende molto probabile l'ipotesi che si tratti di una base di ambone. Anche se non se ne sono trovati lacerti in situ, la corsia doveva essere musaicata poiché si è potuto constatare un sottofondo uguale a quello della navata e alla stessa quota in tutti i saggi eseguiti. ${ }^{58}$

La prima vera solea però è quella parzialmente esplorata dallo Gnirs e in seguito scavata e studiata dal Brusin ${ }^{59}$ che la riferiva all'inizio del secolo V: questa, rialzata di $\mathrm{cm} 15$ sul piano della navata e ornata da musaici che variano di tratto in tratto, è contenuta da spallette di muro che si concludono ad occidente con due basi allargate da pilastrini (fig. 25). Di una
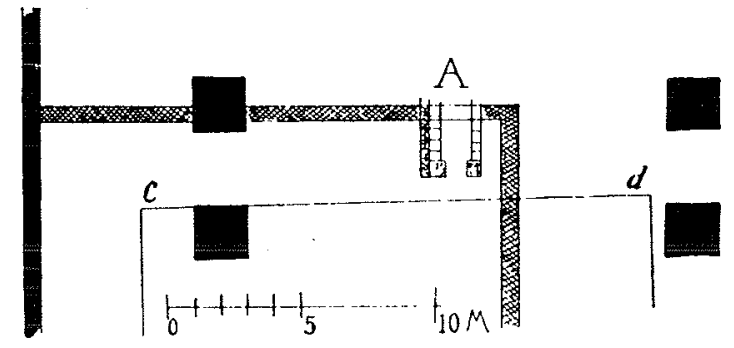

Fig. 25. basilica postteodoriana, resti della solea rilevati dallo Gnirs.

successiva fase della solea a livello superiore di circa $\mathrm{cm} 20$ rimangono tracce nei muretti esterni a quelli della precedente e nel musaico con pelte a gancio entro il pannello destinato all'altare ( $\mathrm{m} 5,72 \times 3$ ), dove il nuovo piano rialzato e le pietre con resti di piombatura a sostegno di qualcosa sacrificano un terzo del tesselato originario a quadrati e a ottogni.

In seguito a queste esplorazioni dunque possiamo concludere che prima della solea vera e propria, larga appena $\mathrm{m} 1,80$ e sviluppata in lunghezza per circa $m 16$, sul pavimento musivo era segnata una corsia che aveva la funzione di condurre dall'altare a un probabile ambone, occupando un lungo tratto della navata centrale per circa $m 28$. Proprio per questo motivo

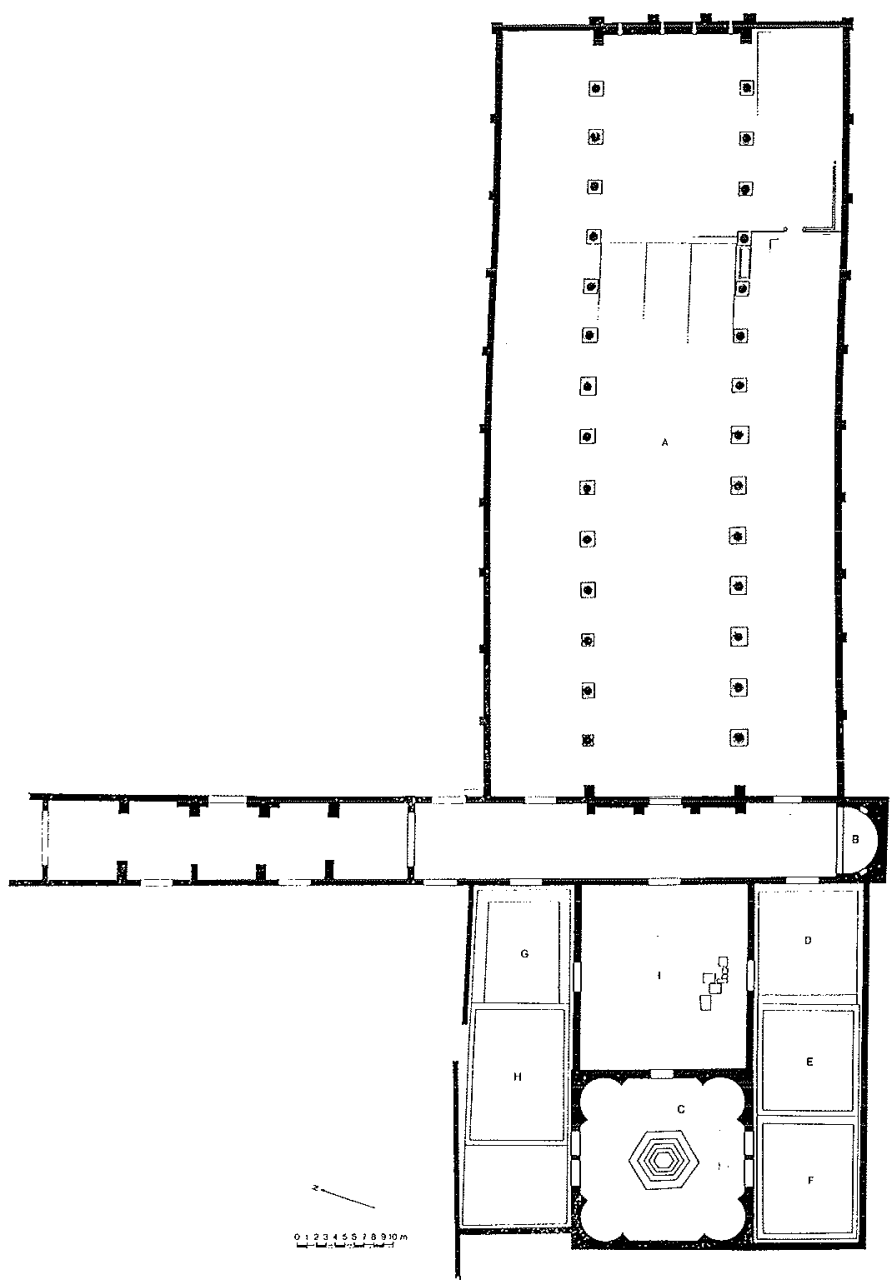

Fig. 26. Aquileia, basilica postteodoriana meritionale (da Bertacchi).

non credo possibile stabilire un'analogia con il corridoio di Monastero, come pensava la Bertacchi, ${ }^{60}$ anche se la distribuzione in due campate del musaico pavimentale sembra determinata proprio da un'esigenza liturgica non meglio definita di introdurre al centro, per tutta la lunghezza dell'aula, una corsia segnata sul pavimento, ${ }^{61}$ come una sorta di "via sacra" all'altare, più che una solea che collega l'altare alla nave.

Anche nello scavo compiuto tra il 1970. eil 1972. nella zona della Postteodoriana meridionale - dalla Bertacchi ritenuta postattilana - si è potuto constatare una tripartizione del pa- 

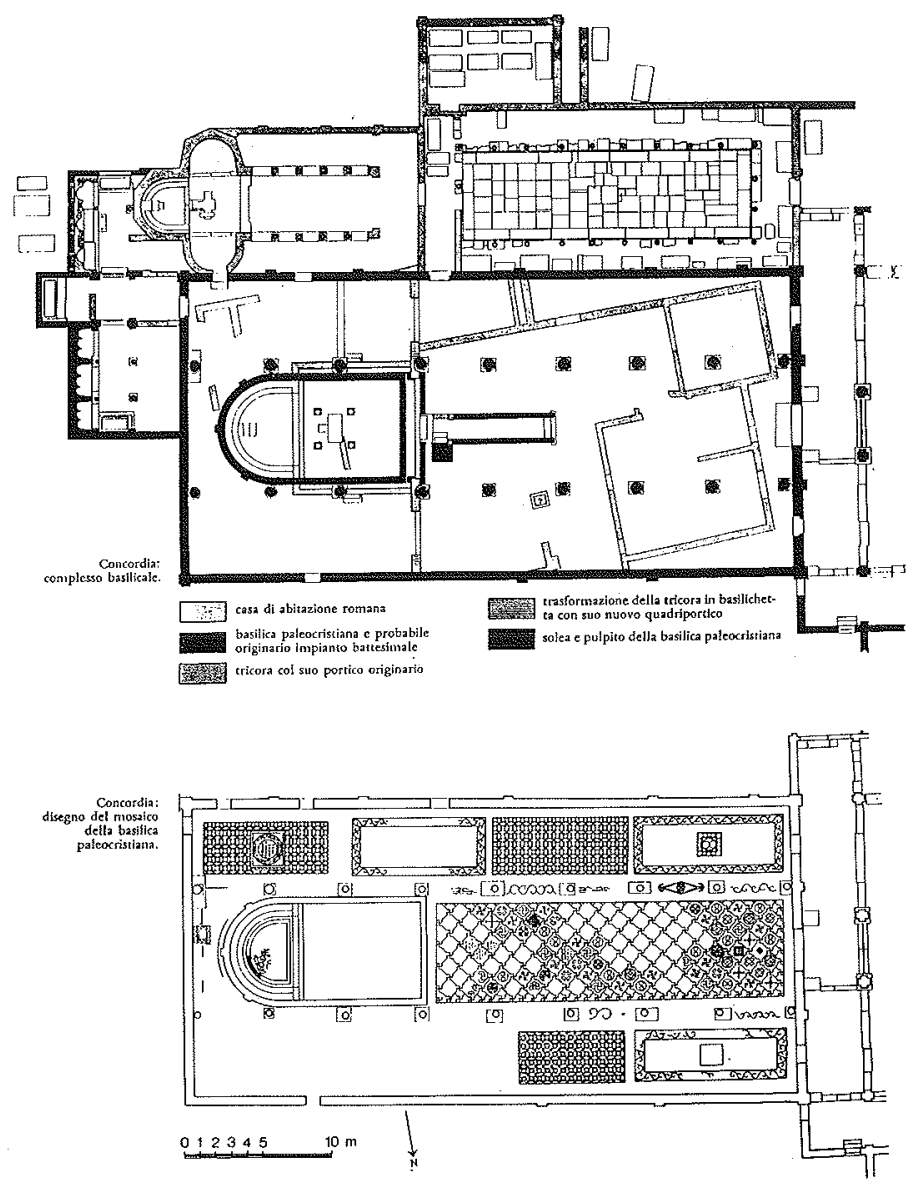

Fig. 27. Concordia, complesso basilicale (da Bertacchi).

vimento musivo nella navata maggiore (fig. 26); la corsia centrale, che giungeva al presbiterio è ampia m 3,70 e lunga almeno $\mathrm{m} 7,50$ come si può ricavare dal tessellato che l'affianca. ${ }^{62}$ Nonostante la variazione delle quote fra i vari lacerti musivi per il diverso cedimento del terreno, la Bertacchi è riuscita a stabilire che questo passaggio centrale era all'inizio soltanto una specie di corridoio segnato sul pavimento, come nella prima fase della Postteodoriana Nord e nella basilica di Monastero. Solo in un secondo tempo fu introdotta la solea e perciò il pavimento della corsia fu rifatto con un musaico a tessere più piccole e a un livello superiore di circa $\mathrm{cm} 12$, documentato da un lacerto musivo su sottofondo gialliccio. ${ }^{63}$

Per quanto riguarda la sistemazione della zona presbiteriale $^{64}$ in mancanza di riscontri archeologici, ci sono solo le ipotesi del Tavano che vi prevede il banco presbiteriale, mentre la terminazione occidentale della solea è irrimediabilmente perduta.

Di notevole interesse anche i resti della solea nella basilica episcopale di Concordia (fig. 27) il cui scavo è stato recentemente edito dalla Fogolari. ${ }^{65}$ Un primo ingresso al presbiterio, lungo $\mathrm{m} 1,85$, risulta nato a livello del suolo con la terza fase presbiteriale e col pavimento musivo che gli si accosta regolarmente; all'interno ne resta solo il sottofondo. In un secondo tempo (inizio sec. VI), forse contestulmente a un allargamento e a una sopraelevazione del presbiterio con la fossa per le reliquie e con la base dell'altare ricavata da un bel lacunare romano, si è verificato un notevole prolungamento della solea, i cui muretti sono stati posti in rottura del musaico e si estendono nella navata per $\mathrm{m} 8,50$; il pavimento interno di questo corridoio manca, ma il suo livello è dato dal limite dell'intonaco sulle pareti di contenimento. La solea ha avuto una terza fase connessa con la sopraelevazione di tutto il pi-

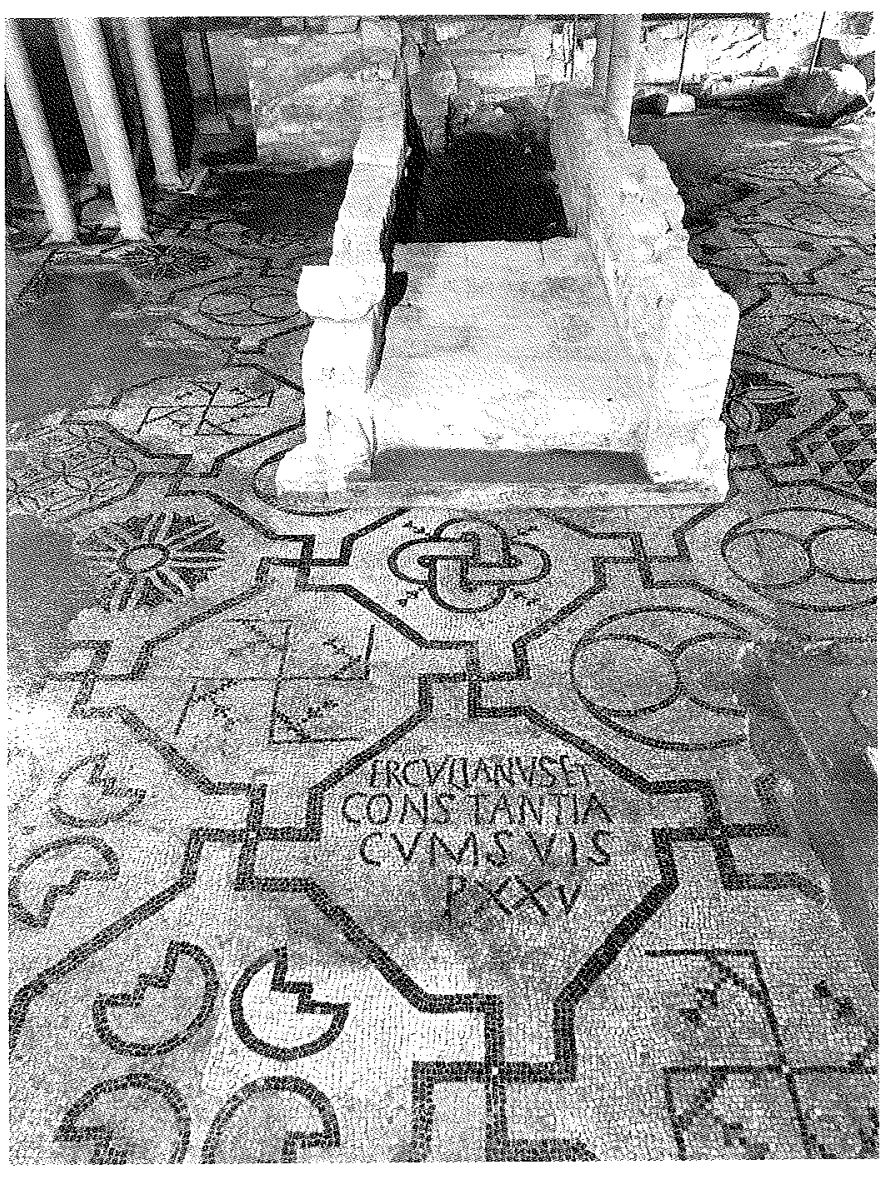

Fig. 28. Concondia, particolare della basilica paleocristiana con pavimento musivo e solea (sec. IV.V) (foto: Ciol)

ano dell'aula in cocciopesto, su cui è stata rialzata $\mathrm{cm} 40 \mathrm{con}$ una copertura in mattoni sesquipedali (fig. 28). E'interessante rilevare che in questo esemplare concordiese la terminazione occidentale non coincideva con un ambone, che anzi fu posto successivamente tra il presbiterio e il lato settentrionale della terza solea (da questa, attraverso alcuni gradini che poggiano sul pavimento in cotto, si accedeva all'ambone). Mi pare di poter dunque escludere che almeno in questo caso sia stata la liturgia della parola a condizionare la presenza della solea.

Le recenti campagne di scavo sul colle di Zuca a IbligoInvillino, nel Friuli, hanno portato alla luce un complesso cultuale riferibile alla prima metà del sec. $V$ con una basilica che presenta caratteristiche utili alla nostra indagine, in quanto la decorazione musiva obbedisce a un piano liturgico riconoscibile in base a precise strutture: l'aula rettangolare, a unica navata, è fornita di banco presbiteriale preceduto da un bema quadrato $(\mathrm{m} 4,85 \times 4,60)$ pavimentato a musaico. Sull'asse del bema uno spazio vuoto indica senza dubbio il posto dell' altare rimosso. Ma quello che a noi più interessa in questa sede sono i segni delle recinzioni che separavano la parte orientale della chiesa resto e soprattutto di quelle che isolavano una sorta di solea sull'asse della navata (figg. 29-29a). Qui il pavimento, di pietre nero-grigie, è decorato da due grandi rettangoli a musaico, distinti da un passaggio centrale (largo $\mathrm{cm}$ 80) compreso entro due cavità (larghe $\mathrm{cm} \mathrm{20}$, profonde $\mathrm{cm} 7$ ) atte a fermare i sostegni di una recinzione (probabilmente di legno) che portava al presbiterio. ${ }^{66}$

Anche per il secolo VI, come si diceva, non mancano in centri adriatici tracce di tale apprestamento per lo più aggiunto a un preesistente pavimento musivo: perciò non è improbabile che si tratti di una ripresa della tradizione locale per influsso della liturgia bizantina in seguito alla riconquista giustiniana. 


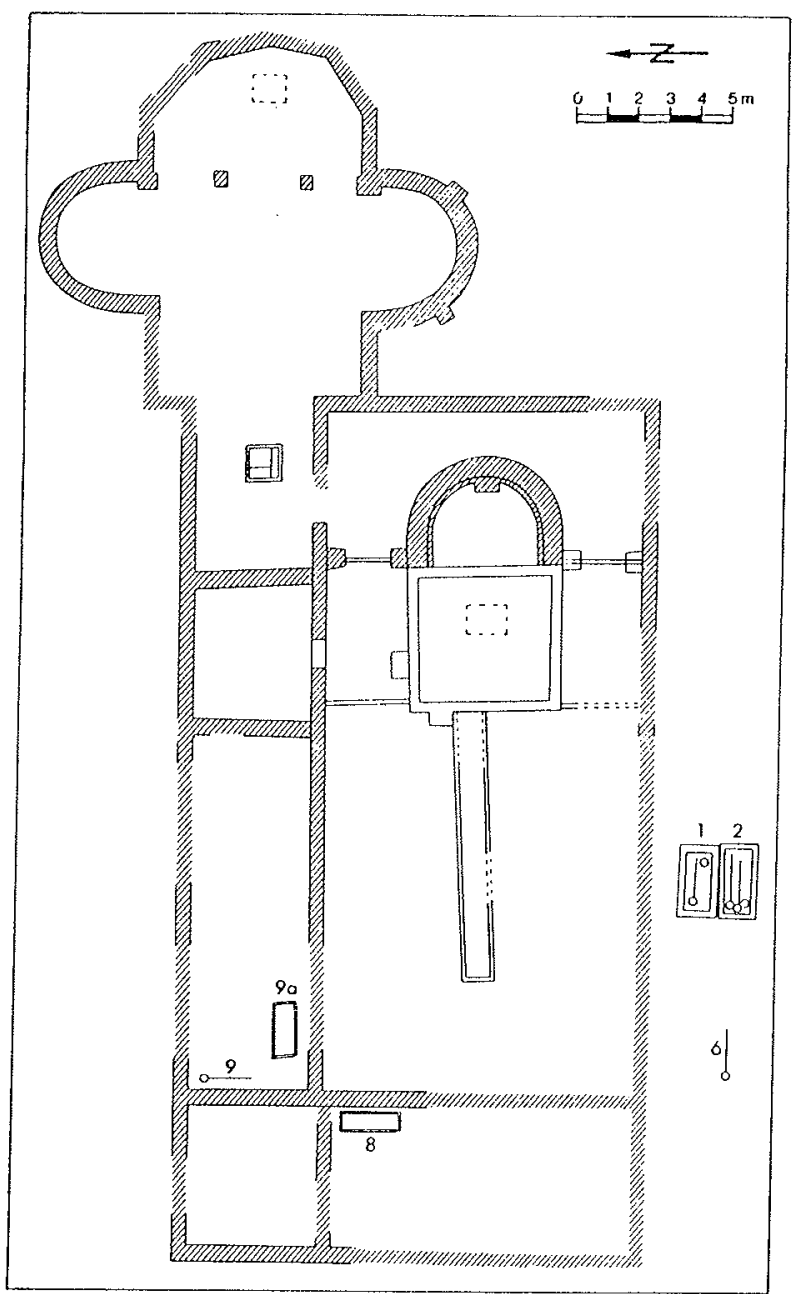

Invillino, Colle di Zuca

Fig. 29. Invillino, Colle di Zuca, basilica paleocristiana pianta (da Bierbraner).

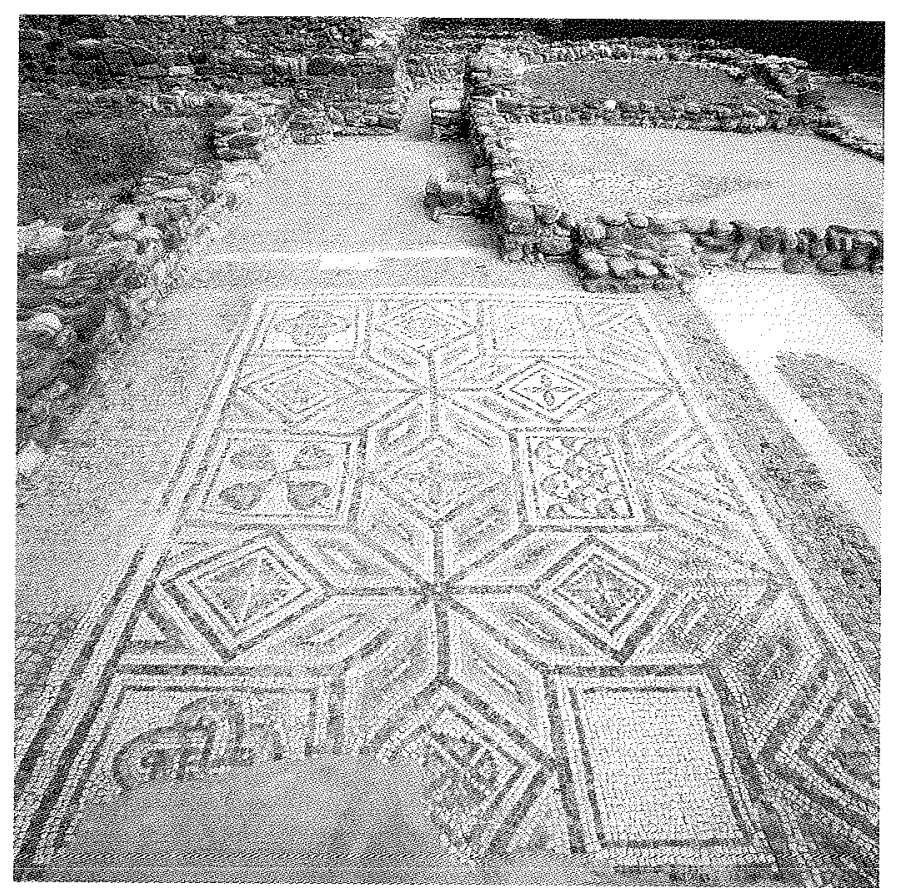

Fig. 29a. Invillino, mosaico.

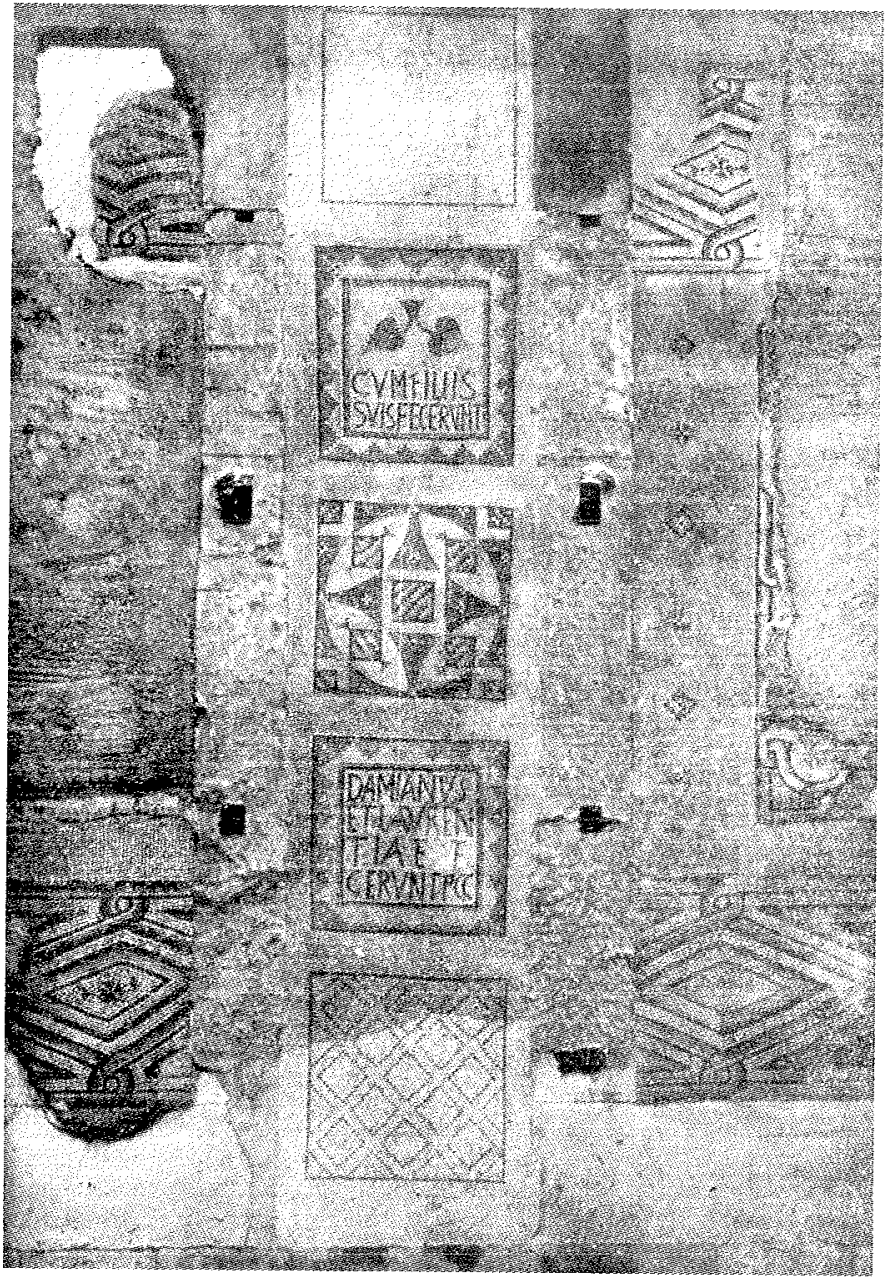

Fig. 30. Pula, Ditomo, resto della solea (da Mirabella-Roberti).

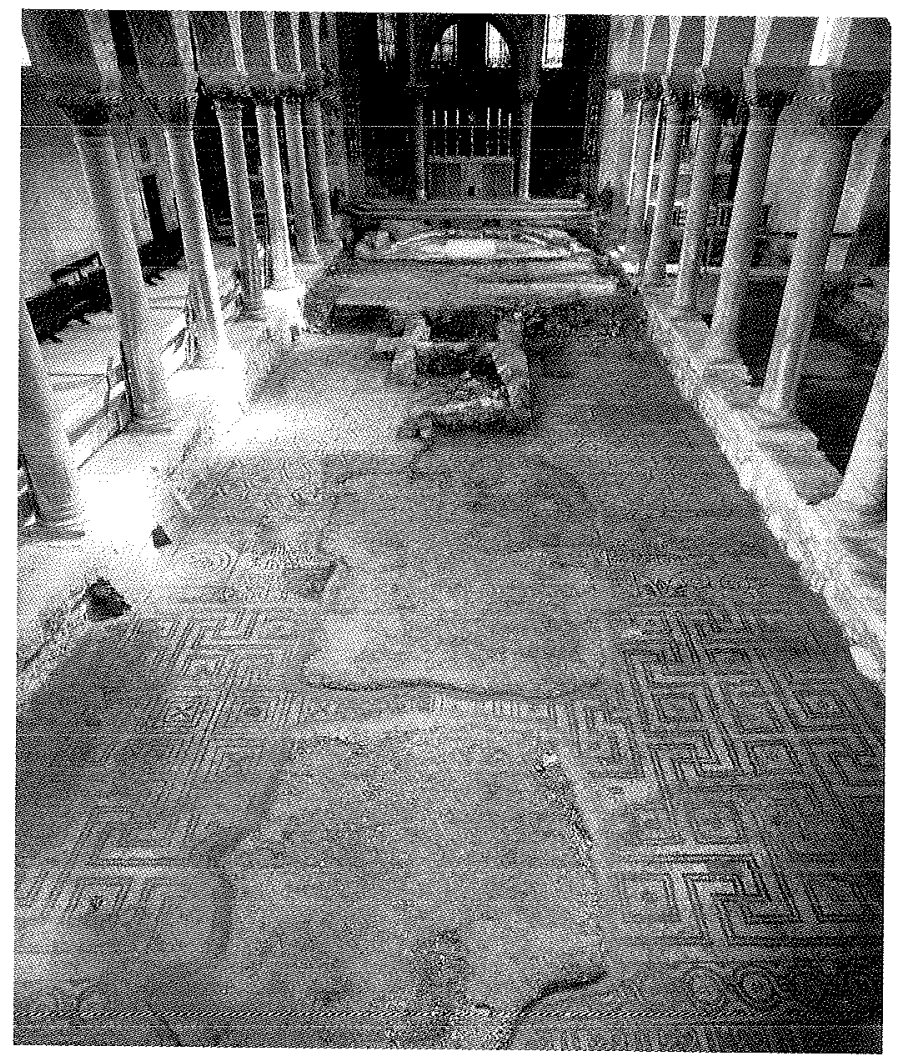

Fig. 31. Poreč, Preeufrasiana, mosaico della navata centrale. 
E'certamente il caso della solea nel Duomo di Grado, nata contemporaneamente al monumento (579), come ha potuto accertare il Mirabella Roberti scoprendo i resti di fondazioni per le cordonate parallele: le sue misure esterne sono di m 4,45 $\mathrm{x} 2$, 57. Durante i restauri, ci si limitò a segnarla sul pavimento per evitare ricostruzioni arbitrarie. ${ }^{67}$

La solea del Dumo di Pola (fig. 30), trovata al livello del pavimento del secolo $V$, è separata dal resto del musaico per mezzo di due strisce di pietra che spezzano l'incorniciatura del campo musivo circostante denunciandone quindi la preesistenza ${ }^{68}$ Le cordonate recano tacche per una serie di plutei che dovevano essere mobile, come attesta un chiaro incasso circolare in corispondenza delle seconde tacche per i pilastrini. Riguardo alla datazione, il Mirabella Roberti riferisce la solea al secolo VI anche in base all'analisi stilistica dei musaici che la ornano, ma non credo altrettanto facile stabilire se sia posteriore alla riconquista giustinianea e quindi condizionata da un eventuale influsso della liturgia orientale, tanto più che dalla metà del sec. VI lo scisma dei Tre Capitoli aveva allentato i legami di Aquileia e dell'Istria con Bisanzio.

Anche nella Preeufrasiana di Parenzo (sec. V) rimangono possibili resti dei muretti laterali di una solea sovrapposti al musaico della navata centrale (fig. 31), a meno si non ritenerli pertinenti a fondazioni di una solea per l'Eufrasiana (sec. VI) o addirittura sepolture di epoca più tarda, come pensava il Molajoli. ${ }^{69}$

\footnotetext{
'H. BRANDENBURG, Chistussymbole in frühchristliche Bodenmosaiken, in "Römische Quartalschrift" 64 (1969), pp. 74-138.

'S. TAVANO, Il recinto presbiteriale nelle aule teodoriane di Aquileia, in “Riv, di Archeologia Cristiana" (d'ora in poi RAC), XXXVI (196)), pp. 111-112. ${ }^{3}$ EUSEBIO DI CESAREA, Storia ecclesiastica e i martiri della Palestina, testo greco con traduzione e note di G. Del Ton, Desclée 1964, pp. 754-755.
} ${ }^{4} \mathrm{~J}$. BRAUN, (Der christliche Altar, I, München 1924, p. 385) afferma però che l'altare aveva la sua postazione nel luogo più venerando della chiesa, cioè nel presbiterio.

${ }^{5}$ P. PASCHINI, Di un supposto scrittore aquileiese del secolo V, Udine 1910, pp. 1-17: le argomentazioni dell'Autore tendone a scalzare le dotte ma inconsistenti ipotesi di P. Braida.

"P. BRAIDA, Sancti Nicetae episcopi Aquileiensis opuscula quae supersunt duo, Udine 1810, p. LV (P.L., XVI, p. 363 ss.)

${ }^{7}$ P.G., L.XVII, coll. 1495-1496.

${ }^{8}$ P.L., XI, col. 476 e n, 4.

${ }^{9}$ P. L. ZOVATTO, Verona paleocristiana, in Verona e il suo territorio, Verona 1960., p. 562. Ma cfr. G.P. MARCHINI, Verona romana e paleocristiana, in Ritratto di Verona. Lineamenti di una storia urbanistica, Verona 1978., pp. 84-87: l'A. riferisce questa seconda basilica al sec. V. Per il dibattito in corso circa la definizione dell'intero complesso di culto con le due basiliche li succedutesi, cfr. G. CUSCITO, Il primo cristianesimo nella "Venetia et Histria". Indagini e ipotesi, Udine 1986. (Antichità Altoadriatiche - d'ora in poi AAAd-XXVIII), pp. 36-37 e n. 89. Sulla funzione della solea, si veda l'ipotesi di G. DE ANGELIS D'OSSAT, Mobilità e funzione delle mense paleocristiane a "sigma". La comunione dei laici, in AAAdVI (1974.), pp. 3I-47. Ultimamente ne hanno scritto C. FIORIO TEDONE, S. LUSUARDI SIENA, P. PIVA, Il complesso paleocristiano e altomedioevale, in La Cattedrale di Verona nelle sue vicende edilizie dal secolo IV al secolo XVI, Verona 1987., pp. 38-43, figg. 18, 21-23, 27: "Questo primo corridoio veronese è stato variamente datato - in relazione ovviamente alle contrastanti assegnazioni proposte per la basilica - e interpretato. Una collocazione alla metà al meno del V sec. pare la più convincente; più complesso in generale è invece il problema della destinazione d'uso dell'aprestamento architettonico."

${ }^{10}$ N. DUVAL, L'architecture chrétienne de l'Afrique du nord dans ses rapports avec le nord de l'Adriatique, in AAAdV (1974.), p. 362. M. MIRABELLA ROBERTI, L'arredo delle basiliche paleocristiane nell'Alto Adriatico e in Africa, ibid., pp. 375-377.

"E. MAREC, Monuments chrétiens d'Hippone ville episcopale de Saint Augustin, Paris 1958., pp. 28-29, 228, n.3. O: PERLER, L'église principale et les autres sanctuaires chrétiens d'Hippone-la-Royale d'après les textes de St. Augustin, in “Revue des Etudes Augustiniennes", 1, 4 (1955.), p. 335: "Il n'y a pas à hésiter sur la disposition de l'autel dans l'église cathédrale d'Hippone. L'autel se trouvait au pied de l'abside dans la nef conformément au texte du sermon... Il était séparé des collatéraux e de la nef centrale par des clôtures "cancelli". La place ainsi isolée était réservée à l'évêque et aux ministres qui la servaient pendant l'oblation...L'autel à forme de table ( mensa) et probablement en bois, était placé au milieu”. A questo punto l'Autore richiama (e lo vediamo più avanti) il passo del sermo 132, l, mensa ipsius est illa in medio constituta, da cui si ricava che in medio è da intendersi al centro del bema posto ai piedi dell'abside sopraelevata e davanti all'assemblea dei fedeli.

12 P.L., XXXVIII, coll. 734-735.

${ }^{13}$ Sermo 392, n. 5=P.L., XXXIX, 1712. Anche il MIRABELLA ROBERTI (L'arredo delle basiliche paleocristiane... cit., p. 378.), che pure sulla scorta deI CECCHELLI ( La basilica di Aquileia, Bologna 1933., p. 208) si serve della citazione di Agostino per confermare le risultanze archeologiche dell'altare in medio e per avallare tale ipotesi anche in mancanza di sicuri dati archeologici, sostiene comunque la presenza del recinto presbiteriale attorno all'altare. ${ }^{34}$ S. TAVANO, Il recinte presbiteriale... cit., p. $105 \mathrm{ss.}$

${ }^{15}$ G. C. MENIS, La basilica paleocristiana nelle diocesi settentrionali della metropoli d'Aquileia, Roma 1958., pp. 116-117., fig. 37. R. PILLINGER, Frühes

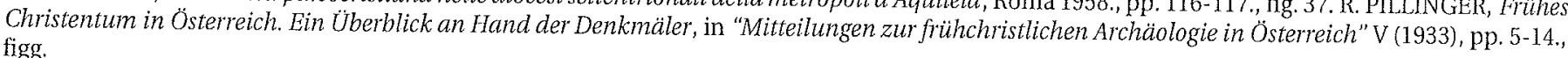

${ }^{16}$ G. BRUSIN, Il posto dell'altare nelle chiese paleocristiane del Veneto e del Norico, in Festschrift für R. Egger, I, Klagenfurt 1952., p. 216. S. TAVANO, Il recinto presbiteriale... cit., p. 116., n. 37. G. BRAVAR, Banco presbiteriale, un arredo delle basiliche del Patriarcato di Aquileia, assente ancora nella metropoli, in "Aquileia Nostra" XXXII-XXXIII (1961-62), coll. 99-108.

${ }^{17}$ M. MIRABELLA ROBERTI, La sede paleocristiana di Orsera, in "Annali Triestini"XV (1944), pp. 31-120.

${ }^{18}$ M. MIRABELLA ROBERTI, L'arredo delle basiliche paleocristiane...cit., p. $37 \mathrm{I}$. 1. M. MIRABELLA ROBERTI, La sede paleocristiana di Orsera cit., p. 68 e n. 98.; ID., La posizione dell'altare nelle più antiche basiliche di Aquileia e di
Parenzo, in RACXXVI (1950), pp. 181-194.; ID. L'arredo delle basiliche paleocristiane... cit. p. 372.

${ }^{20}$ S. TAVANO, Il recinto presbiteriale...cit., p. 111.

${ }^{21} \mathrm{G}$. BRUSIN, Il posto dell'altare...cit., p. 216 ss.

${ }^{22}$ G. C. MENIS, Il complesso episcopale teodoriano di Aquileia e il suo battistero, Udine 1986.

2:3 Il fatto che dalla metà del secolo IV si sia voluto sostituire la Teodoriana Nord con una basilica maggiore, la Postteodoriana settentrionale, potrebbe tornare a favore di quest'ultima ipotesi, in quanto si rileva generalmente la tendenza a non abbandonare la primitiva sede di culto, talora legata a ragioni sacrali che possono anche sfuggire. A ciò si potrebbe obiettare però che la chiesa attuale sorge sull'area della Teodoriana e della Postteodoriana meridionale, ma potrebbe essere frut to di una circostanza fortuita e di una soluzione di continuità dovuta agli sconvolgimenti verificatisi dal secolo $\mathrm{V}$ in poi. 
${ }^{24}$ Concordo col MIRABELLA ROBERTI, (La posizione dell'altare... cit., p. 188) quando afferma che i quattro tasselli in pietra sono imposte di un altare e non fondamenta di un ambone, come vorrebbe non senza motivate ragioni il BRUSIN (Il posto dell altare..c

apostoli e alla basilica apostolorum, cfr. S. TAVAN
${ }^{25} \mathrm{G}$. BRUSIN, Il posto dell'altare...cit., p. $212 \mathrm{ss}$.

${ }^{26}$ S. TAVANO, Il recinte presbiteriale...cit., p. 111 ss. ID., Aquileia e la "domusecclesiae", in "Rivista di Storia della Chiesa in Italia" XXV (1971), n. 2, p. 14. ${ }^{27}$ M. MIRABELLA ROBERT, Osservazioni sulla basilica postteodoriana settentrionale di Aquileia, in Studi in onore di A. Calderini e R. Paribeni, III, Milano-Varese 1957., p. 871 ss.

${ }^{28}$ Ibid., p. 873.

${ }^{29}$ P.L., LXVIII, col, 365 ss. G. VALE, Il vescovo S. Niceta e le norme per le scholae cantorum nella chiesa di Aquileia, in "Canentes Domino in organis", 1925., pp. 24-25. Anche Eugippio (Vita S. Severini, 12,3) ci attesta per il sec. V-VI l'ordine seguito nel canto liturgico: omnibus in ecclesia congregatis unusquisque in ordine suo psallebat ex more.

${ }_{30}$ M. MIRABELLA ROBERTI, La posizione dell'altare...cit., p. 192, n. 33; in realtà si tratta di un motivo "a bipenni" e a cerchi; quello solitamente detto "a onda subacquea" nasce da filari di pelte contrapposte. Tuttavia anche il primo potrebbe forse suggerire un effetto marino.

${ }^{31}$ Il pannello sicuramente destinato alla collocazione dell'altare nella Postteodoriana Nord infatti segue la normale forma della mensa. Per le fondazioni del muro trasversale nell'aula Sud di Parenzo, v. G. BOVINI, Le antichità cristiane della fascia costiere istriana da Parenzo a Pola, Bologna 1974., pp. 8384., con bibliografia precedente.

32 M. MIRABELLA ROBERTI, La sede paleocristiana di Orsera...cit., pp. 88-95., figg. 3, 20, 21. R. FARIOLI, Pavimenti musivi di Ravenna paleocristiana, Ravenna 1975., p. 47.

${ }^{33}$ S. G. XYDIS, The chancel barrier, solea and ambo of Hagia Sophia, in "The Art Bulletin" XXIX (1947.), 1, pp. 1-24.

34 P.G. LXXXIV, coll. 2119-2263. Per la trad. italiana, cfr. A. VENIERO, Paolo Silenziario, Catania 1916. Verso la fine della composizione, in uno dei più bei passi, l'Autore, dopo aver nota to l'effetto dell'ambone nella chiesa, descrive la struttura che lo congiungeva al cancello del presbiterio e viene così a parlare di un lungo passaggio fra l'ultimo gradino dell'ambone e le porte del cancello.

${ }_{35}$ PSEUDO-DIONIGI AREOPAGITA, Epistola VII, P.G., III, col. 1088.

${ }^{35} \mathrm{G}$. CUSCITO, Aquileia e la solea nelle basiliche dell'Italia settentrionale, in "Aquileia Nostra"XXXVII (1967), coll. 87-140. Un tale aggiornamento degli studi su questo problema era già stato auspicato da M. MIRABELLA ROBERTI, Osservazioni sulla basilica postteodoriana settentrionale di Aquileia, cit., p. 874. Tuttavia le recenti scoperte archeologiche al riguardo ci avevano già obbligato a riprendere in esame la questione: G. CUSCITO, Riquardi musivi a destinazione liturgica nelle basiliche paleocristiane dell'Alto Adriatico, in AAAdVIII (1975), pp. 177-216. Per la solea di S. Tecla a Milano, si veda M. MIRABELLA ROBERTI, La cattedrale antica di Milano e il suo battistero, in "Arte Lombarda" VIII (1963), pp. 72-98. Per la solea di Verona, cfr. supra, n.9.

${ }^{37} \mathrm{G}$. CORTESI, La chiesa di Santa Croce di Ravenna alla luce degli ultimi scavie ricerche, in Corso di cultura sull'arte ravennate e bizantina, XXV (1978), pp. 69-70. S. GELICHI, Nuove ricerche archeologiche nella chiesa di Santa Croce a Ravenna, in XXXVI Corso sull'arte ravennate e bizantina, Ravenna 1990, pp. 195-208 (l'A. non si sofferma però sul problema della solea). R. OLIVIERI FARIOLI, Il recento presbiteriale delle chiese di Classe, in Atti del Convegno Intern. di Studi sulle Antichità di Classe, Faenza 1968., pp. 491-494: l'A. però si soferma sul bema con solea della chiesa di S. Severo, costruita in pieno dominio esarcale secondo i moduli dell' architettura giustinianea.

${ }^{33} \mathrm{Ch}$. BONNET, Baptistères et groupes épiscopaux d'Aoste et de Genève: évolution architecturale et aménagements liturgiques, in Actes du XIe Congrès Intern. d'Arch. Chrétienne, II, Città del Vaticano 1989., pp. 1407-1426. Ch. BONNET - R. PERINETTI, Aoste aux premiers temps chrétiens, Aoste 1986., pp. 18-19., 36.

${ }^{39}$ M. MIRABELLA ROBERTI, Indagini nel duomo di Pola, in RACXXIII-XXIV (1947-48), p. 225.

* M. MIRABELla ROBERTI, Grado. Piccola Guida, Trieste 1964., p. 6.

${ }^{41}$ M. MIRABELLA ROBERTI, Osservazioni sulla basilica postteodoriana settentrionale... cit. L. BERTACCHI, Un decennio di scavi e scoperte di interesse paleocristiana ad Aquileia, in AAAdVI (1974), pp. 72-77.; EAD., La basilica postteodoriana di Aquileia, in "Aquileia Nostra" XLIII (1972), coll. 61-88. EAD, Architettura e mosaico, in Da Aquileia a Venezia, Milano 1980., pp. 226-227. Per la solea Postteodoriana meridionale, ritenuta dalla Bertachi postattilana si vedano L. BERTACHI, La basilica postattilana di Aquileia, in "Aquileia Nostra"XIII (1971), coll. 23, 47-50. S. TAVANO, Aquileia cristiana, Udine 1972., (AAAdIII), pp. 65-68. In seguito però la BERTACCHI (Architettura e mosaico cit., p. 231) ha ritenuto di dover escludere che si trattasse di una solea vera e propria, dato che il tema decorativo del musaico "è da campo e non da fascia, date le dimensioni che raggiungono $\mathrm{i} m$. 3,70 di larghezza e dato che il mosaico si trova allo stesso livello del restante pavimento". Per la basilica del Fondo Tullio o della Beligna (in cui è forse da riconoscere la Basilica A postolorum), contrariamente al TAVANO (Aquileia cristiana cit., pp. 148-149), la BERTACCHI (Architettura e mosaico cit., pp. 245-246) ritiene di poter individuare una solea limitata da una recinzione, di cui sono state rilevate le tracce lungo la navata centrale per quasi metà della sua lunghezza.

${ }^{42}$ G. FOGOLARI, La maggior basilica paleocristiana di Concordia, in AAAdVI (1974.), pp. 289, 291.

${ }_{43}$ H. SWOBODA - W. WILBERG, Bericht ïber die Ausgrabungen in Grado, in "Jahreshefte des oesterreichischen archäologischen Institut", IX, (1906.), Beiblat, coll. 1-24., figg. 1, 2, 3, 6, 9. I due scopritori riferivano appunto al VI secolo la prima fase della basilica con la solea; ne anticipano invece la datazione almeno di un secolo S. STUCCHI, Le basiliche paleocristiane di Aquileia, in RACXXIII-XXIV (1947-48), p. 200; G. BRUSIN e P. L. ZOVATTO, (Monumenti paleocristiani di Aquileia e di Grado, Udine 1957., pp. 156., n. 157, 503-504); M. MIRABELLA ROBERTI, (La più antica basilica di Grado, in Arte in Europa. Scritti di storia dell'arte in onore di E. Arslan, Milano 1966., pp. 112, n. 13 (ma cfr. dello stesso Osservazioni sulla basilica postteodoriana settentrionale...cit., p. 874) e L. BERTACCHI, Architettura e mosaico cit., p. 304.

${ }^{44}$ V. BIERBRAUER, Gli scavi a Ibligo-Invillino nel Friuli. Campagne degli anni 1972-73. sul Colle Zuca, in "Aquileia Nostra"XLIV (1973), coll. 89-92; ID., Invillino-Ibligo in Friaul, II, München 1988., pp. 60-69.

${ }^{45} \mathrm{E}$ ' un'osservazione già avanzata da A. GNIRS, Zur Frage der christlichen Kultanlagen aus der ersten Hälfte des vierten Jahrhunderts im österreichischen Küstenlanden, in "Jahreshefte des Österreichischen archäologischen Instituts" XIX-XX (1919.), coll. 199-201, figg. 89-92. L'A. considerava al riguardo anche le tracce di una simile sistemazione nella chiesa di S. Michele di Bagnole presso Pola, pubblicata da D. RISMONDO (La primitiva chiesa di S. Michele di Bagnole presso Dignano, in AMSIXXIV, 1908., pp. 352-373, pianta a p. 357) e di datazione assolutamente incerta. Anche P. TESTINI (Archeologia cristiana, Bari 1980., p. 598, fig. 295) propone una chiusura di presbiterio secondo il modello offerto dalla capsella di Pola. Sbagliava tuttavia - sia pure in buona fede - lo Gnirs quando riteneva di poter mettere in relazione con l'immagine del cofanetto di Pola le prime risultanze allora emerse nella Postteodoriana Nord di Aquileia: solo le indagini successive infatti hanno potuto mettere qui in luce l'esistenza della solea del primo tipo, lunga e stretta.

${ }^{4 t}$ Anche per la bibliografia precedente, cfr. L. BERTACCHI, Architettura e mosaico cit., p. 316. 
${ }^{47}$ G. C. MENIS, La basilica paleocristiana nelle diocesi settentrionali della metropoli d'Aquileia cit., p. 89, fig. 23 e tav. IV. R. PILLINGER, Frühes Christentum in Österreich...cit. fig. 38.

${ }^{48}$ Ch. BONNET, Baptistères...cit., pp. 1412, 1416.

4.) H. KRAELING, Gerasa, City of the Decapolis, New Haven 1939., pp. 189-199.

${ }^{50} \mathrm{G}$. CUSCITO, Aquileia e la solea...cit., col. 125 ss.; ID., Riquadri musivi...cit., p. 186.

${ }^{51}$ I. B. DE ROSSI, Inscriptiones christianae urbis Romae septimo saeculo antiquiores, II, Roma 1888., pp. 295-296. DACL, V, col. 470.

${ }_{52}$ TH. F. MATHEWS, An early Roman chancel arrangement and its liturgical functions, in AAC, XXXIV (1968.), pp. 73-95.

${ }_{53}$ G. MATHIAE, S. Pietro in Vincoli, Roma 1960., pp. 10-20.

${ }^{54}$ L. FORTUNATI, Relazione generale degli scavi e scoperte fatte lungo la via Latina, Roma 1859.

${ }_{55}$ R. KRAUTHEIMER, Corpus Basilicarum Christianarum Romae, I, Roma 1937., pp. 118-143., tav. XIX.

${ }^{56}$ A. FERRUA, La basilica del papa Marco, in "La Civiltà Cattolica" XCIX (1948), pp. 503-513.; ID., La Schola Cantorum, in "La Civiltà Cattolica" CXIII (1962.), pp. 250-258. R. KRAUTHEIMER, Corpus Basilicarum Christianarum Romae, II, Roma 1962., pp. 232-235., fig. 179. Ultimamente però M. TRINCI CECCHELLI ritiene di dover datare al sec. VIII la fase della basilica con la solea.

${ }^{57}$ R. KRAUTHEIMER, Corpus Basilicarum Christianarum Romae, II, Roma 1962., pp. 262-267.

${ }^{58}$ L. BERTACCHI, La basilica postteodoriana...cit., col. 70.

${ }_{59}$ A. GNIRS, Zur Frage...cit., coll. 199-200. G. B. BRUSIN, Gli scavi di Aquileia cit., pp. 189-191.; ID., Monumenti paleocristiani di Aquileia e di Grado cit. pp. 150-158. Egli, prima degli accertamenti della Bertacchi, aveva intravisto che la solea, successivamente rialzata di cm 15 sul piano della navata, era originariamente solo una corsia segnata sul pavimento: infatti gli elementi musivi ai lati dimostrano di finire compiutamente senza invaderla e il disegno è diverso nelle campate distinte dal lungo corridoio, mentre rimane inalterate per tutto il resto della navata là dove esso non giunge. Alle pp. 154-156 l'A. corregge il rilievo della pianta VI a, cui è da sostituire, per la zona dell'altare, la fig. 65 che documenta il nuovo piano rialzato connesso con la seconda sopraelevazione della solea di $\mathrm{cm} 20$ a danno del tessellato originario, come è segnalato solo nel rilievo pubblicato dal Mirabella Roberti nel 1957.

${ }^{80}$ L. BERTACHI, La basilica postteodoriana...cit., col. 70.

(1) EAD, La basilica di Monastero di Aquileia, in "Aquileia Nostra" XXXVI (1965), coll. 93-94 e tav. 1.

${ }^{62} \mathrm{EAD}$, La basilica postattiliana...cit., col. 23 e tav. II; EAD., Architettura e mosaico...cit., p. 231. S. TAVANO (Aquileia cristiana cit., pp. 65) dall'ampiezza di questa corsia, constata un'evoluzione rispetto alla solea della Postteodoriana settentrionale, che era larga, comprese le spalette, solo $\mathrm{m} 1,80(1: 9,8$, rispetto alla larghezza della navata). In rapporto alla larghezza della navata, che è di m 11,70, la corsia e in seguito probabilmente anche la solea della Postteodoriana meridionale $(1: 3,9)$ ricorda piuttosto quella della basilica milanese di S. Tecla $(1: 3,2)$. Su una via di mezzo la solea del duomo di Verona $(1: 6,6)$ o quella della basilica di Piazza a Grado $(1: 6,4)$. Al primo gruppo si avvicina la solea di Concordia $(1: 4,2)$.

${ }^{63}$ L. BERTACCHI, La basilica postteodoriana...cit., col. 70 .

${ }^{64}$ S. TAVANO, Aquileia cristiana cit., p. 65.

${ }^{65} \mathrm{G}$. FOGOLARI, La maggior basilica paleocristiana di Concordia cit., pp. 289-291., EAD., in Iulia Concordia dall'età romana all'età moderna, Treviso 1978., pp. 200-204; L. BERTACCHI, Architettura e mosaico cit., pp. 314-331.

${ }^{65} \mathrm{~V}$. BIERBRAUER, Gli scavi...cit., coll. 89-92., ID., Invillino-Ibligo...cit., pp. 60-69.

${ }^{67}$ M. MIRABELLA ROBERTI, Grado. Piccola Guida cit., p. 6.

${ }^{68}$ M. MIRABELLA ROBERTI, Indagini nel duomo di Pola cit., p. 225.

${ }^{6.9}$ B. MOLAJOLI, La basilica eufrasiana di Parenzo, Parenzo 1940., p. 21.

\section{SVETIŠTA RANOKRŠĆANSKIH CRKAVA NA SJEVERNOM JADRANU}

\section{SAŽETAK}

Prije svega, treba naglasiti da je problem liturgijske opreme u kršćanskoj bazilici vezan uz širi liturgijski prostor i crkveni obred, a nerijetko i uz karakter samog obreda i onoga tko ga je obnašao, o čemu danas imamo vrlo oskudna saznanja. Ne treba, stoga, zanemariti činjenicu da su rezultati ovih istraživanja zasnovani na rijetkim otkrivenim tragovima i oskudnim podacima arheoloških istraživanja, tako da je moguće postaviti samo određene hipoteze, a nikako donositi neke konačne zaključke.

Novija istraživanja problema zahtijevaju iscrpne analize vodeći računa 0 :

- najvažnijim elementima koji u svijetu antičkog kršćanstva pa sve do danas, čine liturgijsku opremu (oltar, katedra, klupa prezbiterija, ambon) i njihovom rasporedu unutar svetog mjesta;

- svjedočanstvima izvora;

- kronološkoj i prostornoj podjeli odabranih spomenika.
Od cjelokupnog liturgijskog inventara, najvažnije mjesto pripada oltaru i katedri, dvama polovima oko kojih se odvija obred: Kristu mistički prisutnom nad oltarom i biskupu, kao nastavljaču apostolskog djelovanja. Stoga je sasvim opravdano istraživanje položaja namijenjenog ovim elementima, ne zaobilazeći ni one manje važne, kao što su ambon ili oltarna menza koji su, u brojnim bazilikama na Istoku, smješteni izvan prezbiterija i odvojeni od svetišta.

Od posebnog su interesa za našu temu dijelovi podnih mozaika vezani uz prostor kršćanskog obreda, gdje je odvijanje liturgije odredeno organizacijom prostora unutar sakralnog objekta. U tom smislu nisu izostala ni sustavna istraživanja smještaja oltara u aulama teodorijanskog kompleksa u Akvileji, shvaćena kao, za sada još eksperimentalno, polazište u odnosu na kasniji razvoj crkvene arhitekture i liturgijskog obreda.

Na isti način, pažnju znanstvenika privlači solea, izdignuće koje vodi od beme u osi glavnog broda što nalazimo u nekim 
antičkim kršćanskim bazilikama osobito na sjevernom Jadranu, kao što je prikazano na poznatoj bjelokosnoj škrinjici iz Pule, iz sredine 5. stoljeća.

Naročito su dobro u izvorima dokumentirane pregrade svetišta čji su tragovi očiti u mozaikalnom podu teodorijanskih aula u Akvileji. Iz nadolazećih vremena, kad se oltari i srodni drveni inventar ugrađuju u zidove, raspolažemo rezultatima arheoloških istraživanja ostataka zidova u svetištu, ostacima pluteja i ukrašenih mramornih pilastara. Dragocjeni stupac Eufrazijevog oltara u Poreču sa fenestellom confesionis pokazuje kako se ispod oltara nalazila confessio ili sepulcretum namijenjeni pohrani relikvija, prema liturgijskom obredu koji je proširio Ambrozije iz Milana.

Pergulae (budući ikonostasi) i ciboriji dobro su dokumentirani na našem prostoru u stoljećima ranog srednjeg vijeka, a u Akvileji i, iznad svega, u Gradu, susrećemo ih već tijekom 5. i 6 . stoljeća u temeljima rijetkih spomenika ili u tragovima imposta na podovima.

Još jedan izvorni dokument od velike rijetkosti i značaja za ovo razdoblje sačuvala je pred-elijanska faza Sv. Marije u
Gradu: cjelovitu podnicu svetišta sa zidanom klupčicom i katedrom prislonjenom uz polukrug apside; malo dalje od njih strše baze četiri stupa koji su nosili ciborij i baza velikog oltara s ugrađenim odlomcima pet stupića na koje je bila oslonjena menza. Prezbiterij iz elijanske faze $(1,10 \mathrm{~m}$ od razine prethodnog poda) zatvoren je, međutim, ogradom s drvenim arhitravom koji je izvorno trebao u sredini imati luk, kako je moguće pretpostaviti na temelju fragmenata sačuvanih $u$ lapidariju. Ovdje se nalaze ulomci ambona i oltarnih menza koji svjedoče o promjenama ukusa od kasne antike do ranog srednjeg vijeka.

Stvarna je novina u ovom razdoblju capella mučenika, odnosno kripta koju je dao sagraditi Maksencije (9. st.) u bazilici Akvilejskog patrijarha, snizivši podnicu na sredini i značajno podignuvši razinu poda novog prezbiterija. Dijelovi njegove ograde danas su dislocirani i ograđuju kapelu Sv. Petra. $\mathrm{Na}$ ovaj način nastavlja se bipolarnost obreda koja je, barem od 5. stoljeća, bila uspostavljena u grupi pratećih gradevina, kao što je to u Concordiji, Poreču, Puli i samoj Akvileji. 